\title{
Anti-Collision Systems in Tunneling to Improve Effectiveness and Safety in a System-Quality Approach: A Review of the State of the Art
}

\author{
Mario Patrucco $^{1}\left(\mathbb{D}\right.$, Enrico Pira $^{1}$, Salvatore Pentimalli ${ }^{1}\left(\mathbb{D}\right.$, Rebecca Nebbia $^{2}\left(\mathbb{D}\right.$ and Achille Sorlini ${ }^{3, *(\mathbb{D})}$ \\ 1 Department of Sciences of Public Health and Pediatrics, University of Turin, 10124 Turin, Italy; \\ mario.patrucco@unito.it (M.P.); enrico.pira@unito.it (E.P.); salvatore.pentimalli@unito.it (S.P.) \\ 2 Department of Management and Production Engineering, Polytechnic University of Turin, 10129 Turin, Italy; \\ rebecca.nebbia@polito.it \\ 3 Tunnel Euralpin Lyon Turin-TELT Sas, 10138 Turin, Italy \\ * Correspondence: achille.sorlini@telt-sas.com; Tel.: +39-347-26-60-237
}

check for

updates

Citation: Patrucco, M.; Pira, E.; Pentimalli, S.; Nebbia, R.; Sorlini, A. Anti-Collision Systems in Tunneling to Improve Effectiveness and Safety in a System-Quality Approach: A Review of the State of the Art. Infrastructures 2021, 6, 42. https://doi.org/10.3390/ infrastructures6030042

Academic Editor: Fabio Rizzo

Received: 13 January 2021

Accepted: 10 March 2021

Published: 12 March 2021

Publisher's Note: MDPI stays neutral with regard to jurisdictional claims in published maps and institutional affiliations.

Copyright: (C) 2021 by the authors. Licensee MDPI, Basel, Switzerland. This article is an open access article distributed under the terms and conditions of the Creative Commons Attribution (CC BY) license (https:/ / creativecommons.org/licenses/by/ $4.0 /)$.

\begin{abstract}
Tunnelling and underground construction operations are often characterized by critical safety issues mainly due to poor visibility and blind spots around large vehicles and equipment. This can lead to collisions between vehicles or between vehicles and pedestrians or structural elements, causing accidents and fatalities. To improve the OS\&H conditions, it is important to investigate the possible introduction of innovative techniques and technologies to reduce the occurrences and consequences of shared spaces (spaces used by both vehicles and pedestrians). For this reason, research was conducted to investigate the possible use of different technologies of anti-collision systems in tunnelling operations. First, to achieve this goal, an extensive review of the literature was carried out in accordance with the PRISMA statement to select the current techniques and technologies used by general anti-collision systems in civil and mining construction sites. Then, the operating principles, the relative advantages and disadvantages, combinations, and costs were examined for each of these. Eight types of systems and many examples of applications of anticollision systems in underground environments were identified as a result of the analysis of the literature. Generally, it was noted that the anti-collision techniques available have found limited application in the excavation sites of underground civil works up to the present day, though the improvement in terms of safety and efficiency would be considerable.
\end{abstract}

Keywords: tunnelling; safety; anti-collision systems

\section{Introduction \\ 1.1. Foreword}

Tunnelling and underground construction operations are often characterized by the presence of narrow and crowded operating areas (e.g., at the face), the simultaneous presence of high-power, free-steering equipment, iterative work cycles, and constraints in the time of completion of the sequences of the excavation phases. These problems can increase the risk of interference between vehicle and pedestrian, impacting production effectiveness and quality and giving rise to work-related accidents [1].

In particular, both underground and in the external yard, mucking, material and spare parts transfer as well as crews marshalling from and to the face make use of free-steering wheeled machines, track-based systems, or special belt conveyors for continuous mucking operations. During the transportation phases, the aforesaid criticalities are increased, and serious safety issues can result, mainly due to poor visibility and blind spots around large vehicles and equipment [2].

To improve the OS\&H conditions, special systems are used to overcome the limitations in the operator's field of view, such as visual systems covering blind spots, relayed to monitors inside the driver's cabin. 
Increased care is moreover devoted to improving the quality of lighting systems along tunnels, reducing problems of glare and areas with very different lighting conditions, along with the installation of acoustic signals or traffic lights along the route, etc.

In more general terms, prevention through design and total quality management of the tunnelling activities $[3,4]$, which also covers materials and personnel transportation, can result in

- preliminary optimization of the system, consisting of track features (width and length, development and grade, quality of road surface and tracks, etc.) and vehicles' number, size, payload, etc., including programs for accurate monitoring and maintenance of the quality of road surface and tracks;

- feasibility analysis of the introduction of physical segregation of pedestrian and vehicle areas through metal barriers or different levels, to eliminate or substantially minimize the risk of interference, i.e., of overlapping of operating areas of the different entities (workers and equipment) present on the construction site [5-7]. In practice, however, the physical segregation, possible in some underground areas cannot yet be generalized, in spite of the improvements in mechanization and automation of many tunnelling phases, in particular at the face if D\&B (drill and blast) excavation is used (see Figure 1).

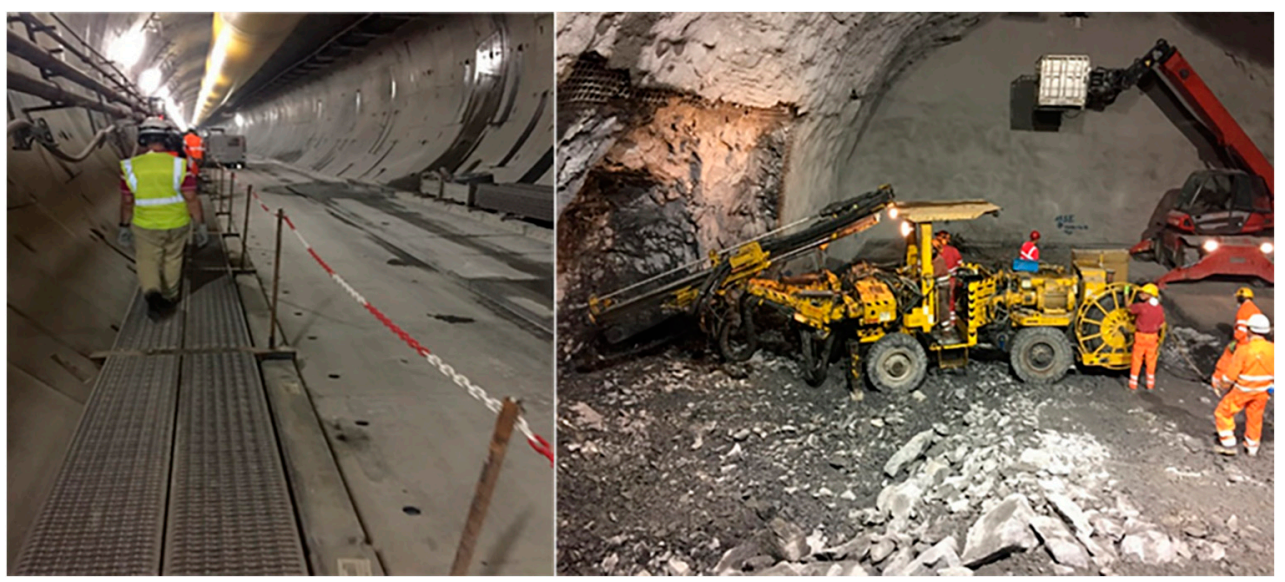

Figure 1. Walkways during tunnel construction with mechanized excavation-TBM (Tunnel Boring Machine) (left). Face excavation with drill and blast method, which involves high concentration of machinery (right).

In addition, the big difference between the various excavation techniques and the large number of boundary parameters that must be considered makes it almost impossible to provide general elements of comparison in terms of OS\&H, and in particular in terms of comparison between the different tunnel driving techniques as stated by Tender M.L., et al. [8]. This confirms the need for a specific risk analysis [9] for every special tunnelling situation, as the potential for vehicle and pedestrian collisions can vary depending on the tunnelling techniques and technologies adopted.

\subsection{Rationale}

The statistics of the Department of Labour OSHA [10] on work-related accidents (see Table 1) confirm that, in the category "Other Heavy and Civil Engineering Construction", which includes tunnelling operations, one of the main causes of accidents and fatalities results from collisions between vehicles and vehicles/pedestrians or structural elements. 
Table 1. Causes of fatal injuries in "Other Heavy and Civil Engineering Construction" sector, occurring in the United States from 2007 to 2018 (source: OSHA-Bureau of Labor statistics).

\begin{tabular}{|c|c|c|c|c|c|c|c|}
\hline \multicolumn{8}{|c|}{ Other Heavy and Civil Engineering Construction-NAICS Code $23799^{1}$} \\
\hline \multirow[b]{2}{*}{ Year } & \multirow[b]{2}{*}{$\begin{array}{l}\text { Total Fatal } \\
\text { Injuries } \\
\text { (Number) }\end{array}$} & \multicolumn{6}{|c|}{ Event or Exposure Leading to Injury ${ }^{2}$} \\
\hline & & $\begin{array}{c}\text { Violence and } \\
\text { Other Injuries } \\
\text { by Persons or } \\
\text { Animal }\end{array}$ & $\begin{array}{c}\text { Transportation } \\
\text { Incidents }^{3}\end{array}$ & $\begin{array}{c}\text { Fire and } \\
\text { Explosions }\end{array}$ & $\begin{array}{c}\text { Falls, Slips, } \\
\text { Trips }\end{array}$ & $\begin{array}{l}\text { Exposure to } \\
\text { Harmful } \\
\text { Substances or } \\
\text { Environments }\end{array}$ & $\begin{array}{l}\text { Contact with } \\
\text { Objects and } \\
\text { Equipment }\end{array}$ \\
\hline 2018 & 21 & - & 6 & - & 4 & - & 5 \\
\hline 2017 & 9 & - & 4 & 1 & - & - & 3 \\
\hline 2016 & 14 & - & 6 & - & 1 & 1 & 4 \\
\hline 2015 & 15 & - & 10 & - & - & - & 4 \\
\hline 2014 & 10 & - & 6 & - & - & - & - \\
\hline 2013 & 21 & - & 7 & - & 3 & - & 8 \\
\hline 2012 & 11 & - & - & - & 7 & - & - \\
\hline 2011 & 11 & - & 7 & - & - & - & 3 \\
\hline 2010 & 10 & - & - & - & - & 4 & 3 \\
\hline 2009 & 16 & - & 8 & - & - & - & 6 \\
\hline 2008 & 9 & - & - & - & - & 4 & - \\
\hline 2007 & 12 & - & 5 & - & - & - & 6 \\
\hline
\end{tabular}

${ }^{1}$ NAICS (North American Industry Classification System) 23799 "Other Heavy and Civil Engineering Construction": tunnel construction activities are classified under this code. ${ }^{2}$ According to BLS (Bureau of Labor Statistics) Occupational Injury and Illness Classification System (OIICS). ${ }^{3}$ Also includes cases in which pedestrians are struck by vehicles (e.g., by track or wheeled vehicles, such as wheel loaders, trains, trucks) during normal functions, namely during transport, regardless of place. ${ }^{4}$ Includes cases where there is contact between a worker and a vehicle or mobile equipment, but not during normal transport (e.g., injuries caused by a part of a moving machine, such as being hit by forklift as it is lifting an item, in this case subcategory "Struck by object or equipment").

The chart from Figure 2, drawn from average percentages of the data in Table 1 showing fatal accidents per year for the reference sector, gives details of the incidence of fatalities resulting from collisions between vehicles or between vehicles and pedestrians or structural elements.

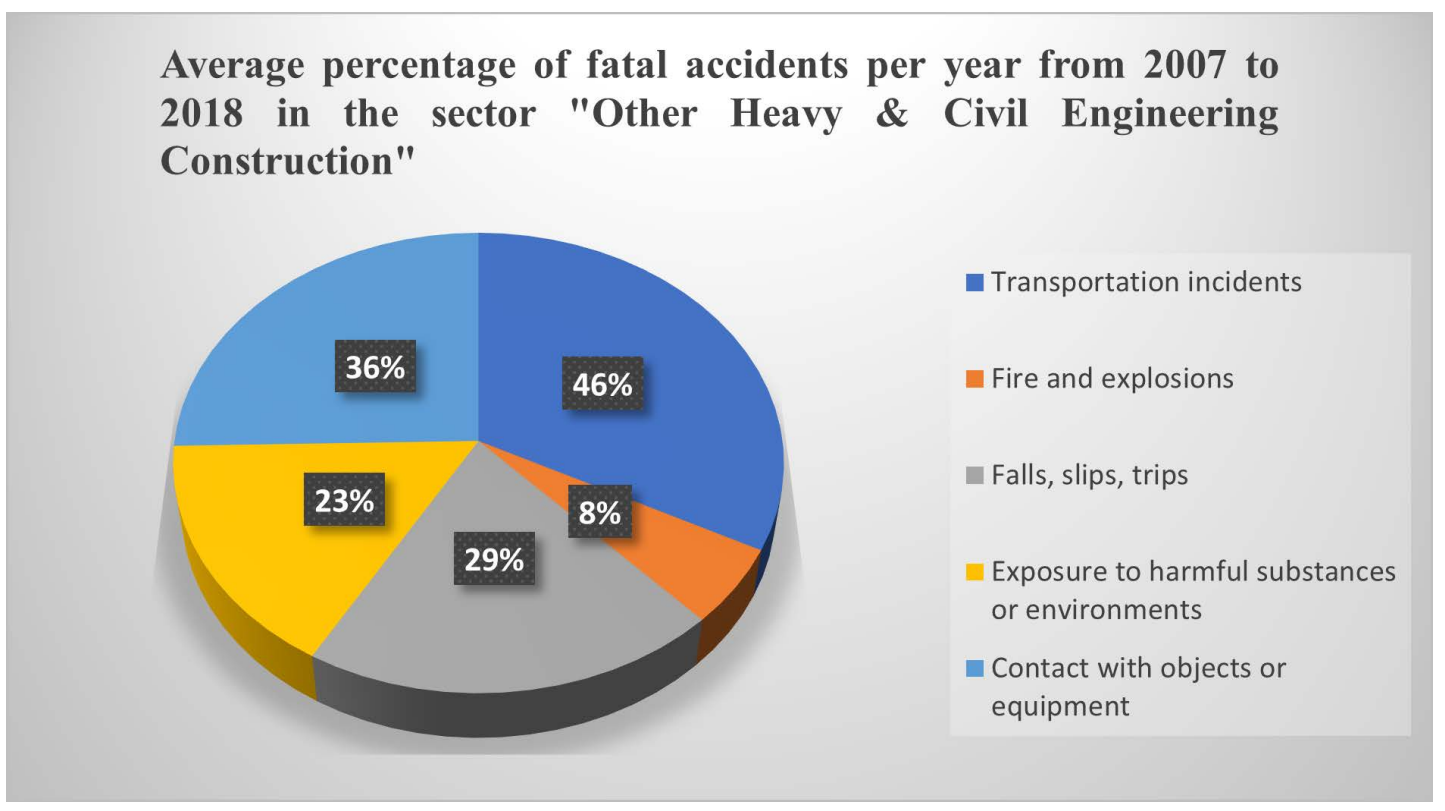

Figure 2. Annual average percentage of accidents by type of cause in the United States (calculated using data from Table 1) in the "Other Heavy and Civil Engineering Construction" sector from 2007 to 2018. 
A significant number of fatalities in the heavy and civil engineering construction sector (in which tunnel construction activities are included) appear to be caused in shared spaces, that is, between free-steering and mobile equipment and pedestrians [11], as is also confirmed by Safe Work Australia (see Table 2).

Table 2. Number of fatal accidents by cause (according to TOOCS-Type of Occurrence Classification System of Australian Government) in "Heavy and Civil Engineering Construction" sector from 2014 to 2018 (combined) (source: Safe Work Australia).

\begin{tabular}{|c|c|c|}
\hline $\begin{array}{c}\text { Construction Subdivision and } \\
\text { Mechanism }\end{array}$ & Number of Fatalities & $\%$ of Fatalities \\
\hline $\begin{array}{c}\text { Heavy \& civil engineering } \\
\text { construction }\end{array}$ & 22 & $\begin{array}{c}14 \% \text { (of total number fatalities } \\
\text { in construction) }\end{array}$ \\
\hline Struck by moving objects ${ }^{1}$ & 9 & $41 \%$ \\
\hline Vehicle collision $^{2}$ & 3 & $14 \%$ \\
\hline $\begin{array}{l}\text { Trapped between stationary and } \\
\text { moving objects }{ }^{3}\end{array}$ & 2 & $9 \%$ \\
\hline Falls from a height & 2 & $9 \%$ \\
\hline Being struck by falling objects & 2 & $9 \%$ \\
\hline Other mechanisms & 4 & $18 \%$ \\
\hline Construction 5 years total & 156 & $100 \%$ \\
\hline
\end{tabular}

${ }^{1}$ Includes cases where pedestrians are struck by moving vehicles or mobile parts of machinery. ${ }^{2}$ This code is assigned to accidents that involve a vehicle (e.g., a tracked or wheeled vehicle) that crashes, overturns, or goes out of control, where injury is the direct result of the accident and the vehicle has contributed significantly. Collision also means impact against any obstacle on the road (e.g., holes, rocks, or other vehicles) but not against pedestrians (listed under "being struck by moving objects", as this concerns injuries to the occupants of the vehicle. ${ }^{3}$ This category includes events in which workers are caught or trapped between stationary and moving objects, where the objects are part of the same machine or equipment.

While, with particular reference to tunnel excavation activities, and as a further confirmation of the critical nature of shared space, the excavation of Alptransit tunnels involved 15 fatalities from 2001 to 2005 (divided between the Lötschberg, Gotthard, and Ceneri tunnels). Of these, eight were associated with transportation, four with equipment and machinery, two with falling rocks, and one with an unspecified cause. Of the eight transport accidents, three were caused by wheeled vehicles (loaders operating in reverse), three by rail transport (derailment of a train carrying wagons filled with excavated material), and two by vertical transport. This experience emphasizes the problem that most accidents in tunnelling activities are related to traffic and transport [12].

Finally, the analysis of an accident that recently occurred in an exploratory tunnel in the Northwestern Alps, carried out by means of the CCCP (Computer aided Cause Consequence for Prevention) [13-15], confirmed the importance of the introduction of the latest technologies as essential prevention measures (see Table 3). 
Table 3. Example of application of the Computer aided Cause Consequence for Prevention (CCCP) approach on a real accident case in the reference context.

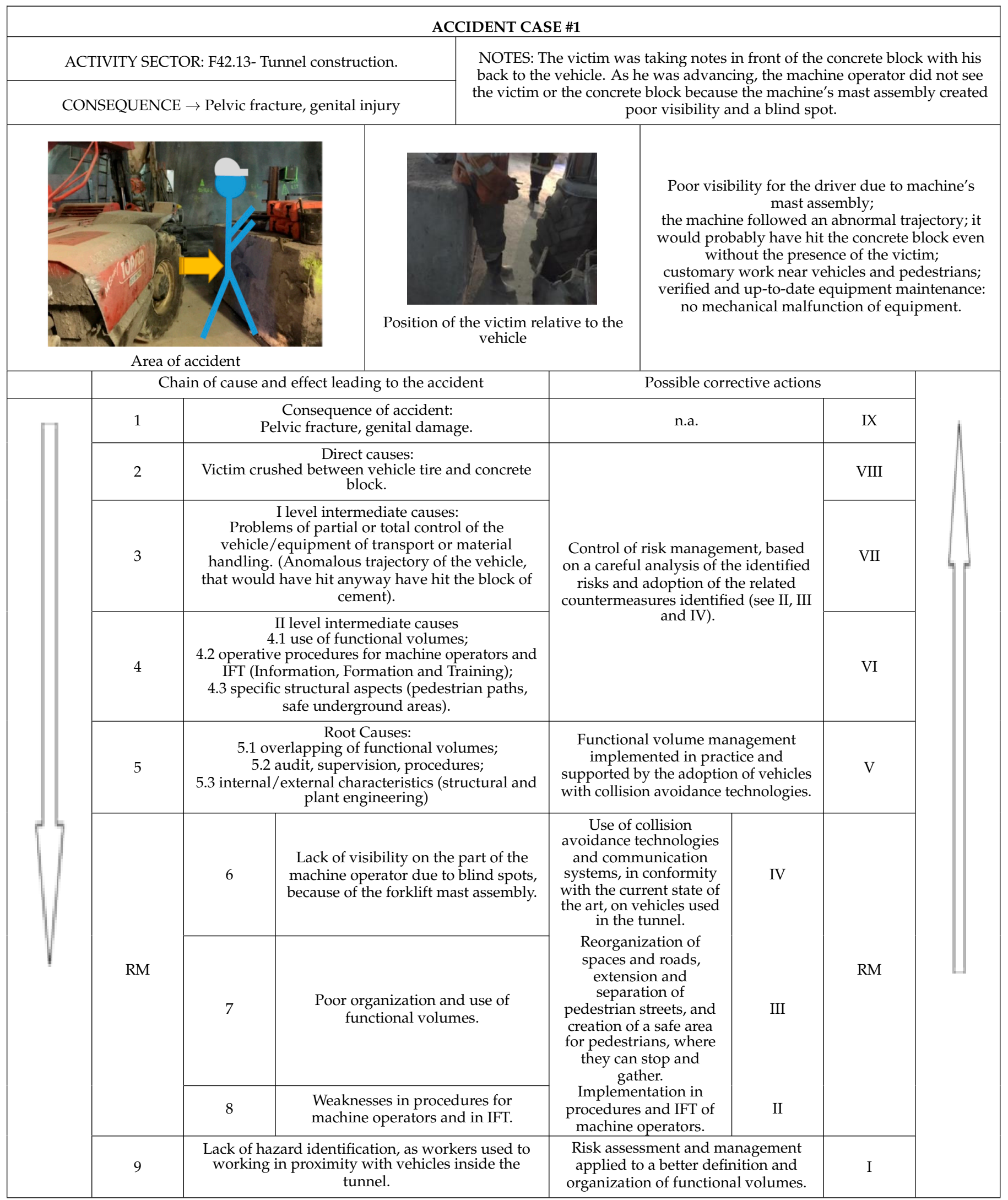


It must be underlined that, even if the accidents database covers a limited number of events, the sample shows that the problem is real and merits effort to control it, taking also into account the small number of total underground operations inside the general sector of construction and mobile activities covered by the 92/57 EEC Directive [16], and the linked fatality investigation records in the statistical databases [10,17].

Moreover, the accidents due to interference involve significant costs because of the ceasing of the tunnelling operations [18].

Hence, it becomes very important to investigate the possibility of introduction of innovative techniques and technologies currently available to reduce the occurrences and consequences of shared spaces, in accordance with the 92/57 EEC Directive. The Directive highlights the importance of coordination of the organizational aspects to manage the risk of interference.

To overcome these problems, research was conducted to provide useful practical guidelines (investigating the possible use of different technologies of anti-collision systems in tunneling operations) in a tunnel excavation [19].

Thus, the paper summarizes the initial results of the study, consisting of a thorough review of the principal anti-collision systems available using different technologies. Together with this overview, examples of application of these systems are also provided, taken from the literature and from the direct experience of the authors, to illustrate the considerable contribution that these systems make to the management of interference in the project implementation phase (given that the use of integrated detection technologies is not always enough to guarantee the absence of risks).

This paper focuses only on systems that can be used for operator-driven equipment; self-guided equipment specially designed for tunnelling operations will be considered in a future research phase.

\section{Materials and Methods}

An extensive review was carried out of the literature to investigate the current techniques and technologies used by general anti-collision systems in civil and mining construction sites. The literature search was performed in accordance with the PRISMA statement [20] on the Google Scholar database. The search terms used included the following keywords: "collision avoidance system", "proximity detection system", "collision warning system", "underground activities" and "tunnel construction". The search yielded 900 articles. Among the 900 references identified, 700 were excluded by title. Of the remaining 200 articles, 132 were excluded because the abstracts were not relevant, 8 were excluded because no full text could be retrieved, 5 because they were grey literature, such as theses, congress proceedings and papers that had not received peer review, and 8 because they were not relevant. Finally, 47 documents were selected (Figure 3). Among the documents selected, 32 concern underground mining environments, as these environments have characteristics very similar to those relating to tunnelling activities, and 15 concern tunnelling activities.

Each of the papers selected were searched for identification of the types of technologies used, the operating principles, and the relative advantages and disadvantages/limitations that may influence their effectiveness in tunnels for the construction of large infrastructural works. In addition, the costs relating to the proposed technologies were taken into account in comparative terms.

Furthermore, some possible advantageous combinations between different techniques or technologies were also taken into account. These advantageous combinations overcome any limitations that the different techniques or technologies may present in difficult environments such as below ground. 


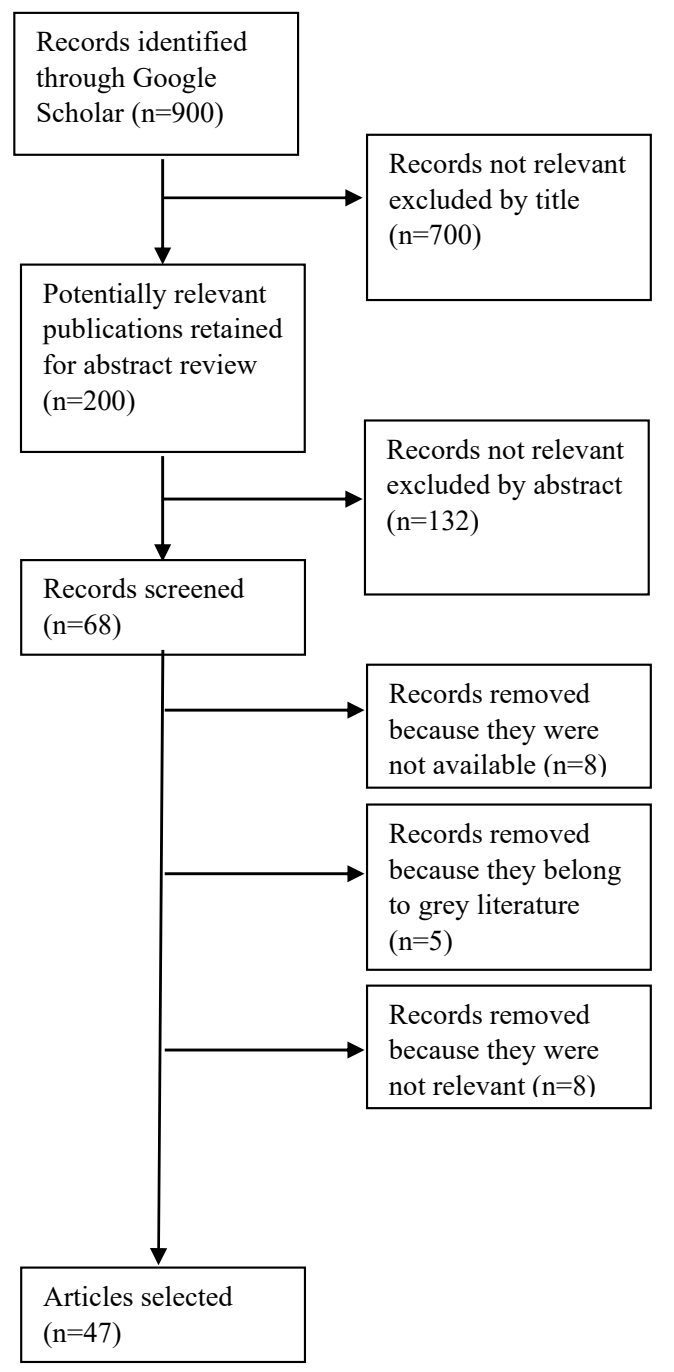

Figure 3. Flow chart of the bibliographic search.

In the present study the vehicle speed represents an important parameter to be taken into account (a procedure-worth adopting in the opinion of the authors-can be established by using an automatic limiter, which prevents exceeding a specified speed in any case, bearing in mind that even self-guided vehicles do not exceed this speed, and if no limits are set, no anti-collision system can guarantee its effectiveness).

In addition, specific ranges of distance (varying depending on the types of systems studied) were examined, enabling the braking or stopping of the vehicle in time to avoid collision (bearing in mind the large inertia of vehicles, which makes it difficult to change direction quickly).

Table 4 shows the range of distances allowed by the technologies covered by this study, consistent with the speeds taken into account and the established goal.

Within these distance ranges, different progressive focus areas can be identified, which, within the same distances, can be adjusted according to the needs of the context such as to allow braking or stopping of the vehicles in time to avoid a possible collision between vehicles or people/vehicles.

Finally, examples regarding the applicability and management of shared spaces with these methods were obtained from the papers selected using the prism method and consulting the websites of the manufacturers of anti-collision systems for underground activities. 
Table 4. Range of distances allowed by technology.

\begin{tabular}{cc}
\hline Technology & Indicative Distance Range \\
\hline Radar & up to $30 \mathrm{~m}$ \\
\hline RFID/RF (Radio Frequency IDentification) & $\begin{array}{c}\text { For low frequencies: from } 10 \text { to } 30 \mathrm{~m} \\
\text { For high frequencies: up to } 100 \mathrm{~m}\end{array}$ \\
\hline Ultrasound & up to $5-8 \mathrm{~m}$ \\
\hline Laser/Lidar & up to $50-80 \mathrm{~m}$ \\
\hline Video cameras & $\begin{array}{c}\text { up to } 100-150 \mathrm{~m} \text { (in conditions of good lighting, } \\
\text { variable according to the light conditions) }\end{array}$ \\
\hline Thermal imager-IR (Infrared) & up to $100 \mathrm{~m}$ \\
\hline Bluetooth Low Energy beacon & up to $10-20 \mathrm{~m}$ \\
\hline GPS (Global Positioning System) & up to $60 \mathrm{~m}$ \\
\hline
\end{tabular}

\section{Results}

\subsection{Techniques and Technologies Used by Anti-Collision Systems}

Eight types of systems were identified: radar, radio frequency (RFID/RF), ultrasound, Bluetooth beacons, video cameras, thermal cameras/infrared rays, GPS, and laser. In addition, two "basic" conditions are specified, which are (1) the constant attention on the part of individuals working underground and of the vehicle operators, including the checking of rear-view mirrors, especially when operating in reverse, and (2) leaky feeders [21,22] (electrical cables designed to radiate), which represent an effective and optimal communication system between vehicles and personnel along the entire tunnel and between the underground environment and the surface to facilitate their location. Table 5 shows the results of the literature review.

Table 5. Results of review of the literature.

\begin{tabular}{|c|c|}
\hline \multicolumn{2}{|r|}{ Radar } \\
\hline Principles and Characteristics & $\begin{array}{l}\text { There are two different types of radar: pulse radar and continuous wave (Doppler radar) [23,24]. } \\
\text { Pulse radar technology systems work by measuring the electromagnetic signals' flight time (pulses) to } \\
\text { determine the distance between radar unit and the object reflecting electromagnetic energy in the detection } \\
\text { area [23-25]. Doppler radar uses the Doppler effect to determine the speed (towards or away from radar) of a } \\
\text { detected object and its distance [24,26]. Single-beam radar is the most common for Proximity Detection } \\
\text { Systems (PDS). Scanning radar systems perform, according to their principle of operation, a scan of a single } \\
\text { beam to produce a two-dimensional (2D) or three-dimensional (3D) image [23]. } \\
\text { The audible alarm is placed in the driver's vehicle cab and is associated with a set of lights on the } \\
\text { dashboard [27]. }\end{array}$ \\
\hline Advantages & $\begin{array}{l}\text { Radar-based collision avoidance systems are appealing due to their high durability and ease of use and } \\
\text { assembly [28]. Moreover, this technology has integration capabilities with multiple antennas [29]. } \\
\text { It is proven that the attenuation of microwave and millimeter wave radar signals by dust, smoke, snow, rain, } \\
\text { and dense fog is negligible, so they offer good flow rate performance (better than lasers), even in adverse } \\
\text { environmental conditions. This makes radar a promising sensor for distance detection, even in low light } \\
\text { conditions such as underground spaces [23,25,26,30-35]. In addition, millimeter wave radar has a shorter } \\
\text { wavelength than microwaves, so the antenna for narrowing and transmitting the radar beam can be reduced } \\
\text { in size, which facilitates installation on the vehicle, as narrow beams make them suitable for closed areas } \\
\text { [33-35]. } \\
\text { Both pulse and Doppler radar are compact and relatively easy to install, and Doppler radar can also measure } \\
\text { vehicle speed (in line with its operating principle, it detects a signal shift frequency generated from an object } \\
\text { within the detection zone) [23,34,36]. Generally, radar is effective for detecting people, other vehicles, large } \\
\text { rocks, and buildings [25]. } \\
\text { Tests have shown that small metal objects worn by a person (e.g., glasses, jewelry, watches) do not affect the } \\
\text { size of the detection area. This is due to the metal elements reflecting the radar waves much better than other } \\
\text { materials, and this could cause differences in detection of the actual object distance. Generally, neither a } \\
\text { person's height nor their body weight affects the width of the detection area, except for the close intervals at } \\
\text { which the test subject walks under the radar beam [27]. } \\
\text { Radar systems can measure distance directly with lower requirements of calculation resources than other } \\
\text { systems [26,32,36] and they do not require workers to adopt wearable components [25]. } \\
\text { Radar systems that can be used for Proximity Detection Systems operate at the microwave band frequency of } \\
\text { 300MHz-40GHz, which is very different to the typical frequencies that can be found in underground } \\
\text { environments, so interference is unlikely [23,25]. }\end{array}$ \\
\hline
\end{tabular}


Table 5. Cont.

\section{Radar}

Millimeter wave radar has a fairly small opening and a width beam narrow enough to allow scanning by mirrors. These mirrors must be relatively large, making a scanning radar system bulky and potentially problematic in underground environments [37].

The proximity of tunnel walls and other objects makes radar use in underground environments problematic due to frequent false alarms $[23,28,38-41]$.

False alarms may be due to the detection of objects that do not represent any danger (e.g., rocks, building materials) $[28,36]$ or due to loud noises or other unwanted object reflection, other than the target [33], causing a sense of frustration in the driver and leading the driver to ignore them [28].

The factors influencing the operational capability are target distance, radar target cross-section, and the medium through which the wave must propagate. Unit positioning with respect to the detected object is highly dependent on the shape and orientation of the object. For example, more energy is returned to the receiver if the radar is pointed perpendicularly at the side of a tractor trailer rather than at a cylindrical tanker or a person $[23,27]$.

High mounting positions require the radar to be angled downwards, reducing the length of the detection area This is dangerous because a person can walk near the machine without being detected, due to the short beam width of the detection $[27,28,42]$.

Special care needs to be taken to mount the sensor so as to avoid/reduce deposits able to form a thick layer, such as dust, oil, mud, ice, or snow. Antennas should be mounted in such a way as to prevent water from accumulating on the antenna or sensor [24]. Such deposits on the active sensor surface may affect its detection function, so precautions should therefore be fitted [43].

Limitations The Doppler radar type cannot, because of its operating principle, detect stationary objects [24]. Radar technology does not provide identification of a human being per se, as it cannot distinguish people from other objects, but only detects a presence $[25,29,33,42,44]$. It is not suitable for very fast motion scenarios [29] and, moreover, constitutes a line of sight technology [25].

Radar requires higher energy consumption than other acoustic and optical sensors [26].

Some obstacles are not suitable for radar beam reflection, such as plastic, dry wood, or objects with large flat surfaces that can reflect the signal away from the radar antenna [25,34]. A vehicle's metal parts reflect much better than human tissue, but the latter, in turn, reflects much better than non-conductive materials, such as timber [41].

Failed recognition may occur when the reflected return wave is so weak that it cannot be detected by the radar system [33]. With microwave radar, it has been shown that large antennas are required in underground spaces, and this is impractical for surface machines [35].

Human exposure to electromagnetic fields generated by radar systems could lead to thermal effects, such as tissue heating or, if too much time is spent near radar antennas, the causing of cataracts (but such effects are not possible at environmental levels of the RF level fields generated by radar systems), or non-thermal effects, such as alteration of calcium ions mobility. Currently, however, there is no evidence that adverse health effects, including cancer, can occur in people exposed to RF field levels equal to or below the limits set by international standards [45].

Most of these systems are already combined with GPS, V2V radio-lidar, recommended for high-speed driving scenarios [26,43]. Another advantageous combination can be made between radar technologies and cameras on heavy vehicles; as the radar is subject to frequent false alarms, it requires an additional method, such as cameras, to verify the cause and exact location of a detected object, with the radar being used primarily for the distance and calculation of the sectors of interest [26-29,32,46].

Advantageous combinations of technologies

Technology costs
Radar-based collision avoidance systems have relatively low to medium costs, but are higher when compared to acoustic ones $[26,28,32,33]$. Millimeter wave radars are priced higher than other types of radar $[31,35]$, while microwave radars have relatively low costs [35].

\section{RFID/RF-Radio Frequency Identification}

This is a technology used in several industries to monitor activities and safe applications [47]. RFID is a generic term to indicate the use of radio waves to identify people and objects. RFID tags are included in RF-based systems, and manufacturers use the tag in different ways. Therefore, it depends on the producer if the system is classified as RFID or simply RF. A common RF-based system that is separate from RFID-based systems is the magnetic field system, which uses low or very-low magnetic field frequencies to produce a stable marking zone [23].

The most common identification method is to store a unique serial number, which identifies the object or person (especially in a vehicle's blind spots) on a microchip connected to an antenna, along with other information, using wireless technology. The antenna enables the microchip to transmit the identification information to a reader that can reconvert the RF signal into a serial number to use it $[23,24,39,47,48]$. Tags with identification codes are worn by workers, and when they enter into a danger zone, they are detected by the reader, so that an alarm alerts the vehicle operator by means of both an audible and visual alarm $[25,39,42,47,48]$. These tags can be worn on belts or helmets or in the cap lamps of underground workers and equipped with rechargeable batteries [47,48]. An RFID tag used for a Proximity Detection System contains an additional circuit that allows it to determine the distance between tag and reader, measured on the basis of the received signal strength (RSSI) [23,24,42].

Depending on the type of energy supply and mode of communication, the tags can be divided into passive, semi-passive, and active. Passive ones are not self-powered and use the back-wave of the reader's radio waves, usually at the same frequency as emitted, to feed information. In semi-passive tags the energy to power the chip is obtained from the battery, but the retro-diffusion is used for communication between tags and reader. Active tags use battery power for communication and internal operations [24,25,42,49]. These devices have been adapted to underground activities, such as mining, in various ways, including vehicle monitoring, personnel monitoring, inventory control, and maintenance interventions, for example through the use of PEDs (Personal Emergency Devices), enabling them to be optimized with a consequent reduction in cost, minimizing possible production losses [24]. 
Table 5. Cont.

\section{RFID/RF-Radio Frequency Identification}

Passive RFID systems are inexpensive and easy to install. The active ones allow a good range of detection of up to about $100 \mathrm{~m}$ (in any case, greater than the passive ones) $[24,25,30,36,39,42,43]$. These systems can also detect tags that are outside the line of sight (for example, around corners) $[23,25]$.

The box that contains the reader and tags is robust, shows no reduction in performance, and requires very little maintenance if properly designed [39,47,50,51].

Low-frequency RFID systems allow for close distances and also are resistant to large metal obstacles $[30,50,52]$, as low frequency signals can penetrate practically anything, including dust, coal, rocks, sprays, metalliferous minerals, and metals. This obviously makes low frequencies the best choice in underground environments $[25,48,53]$.

Ultra-high frequency RFID systems allow long-range use and are reliable and cost-effective for both surface and underground [30,52].

Advantages

Tag-based RFID systems, operating at various frequencies, are popular for collision avoidance systems due to their low number of false alarms $[40-42,44,47,48,54]$ and can distinguish workers from other objects, thanks to the unique tag identification code [27]. They have the ability to detect multiple tags simultaneously with high efficiency, and the detection area is adjustable $[36,39,47,48]$. The availability of the system increases through the use of multi-channel transmission [43]. The use of multiple tag readers allows an increase in area coverage, accuracy in position estimation, and increased probability of "intruders" detection [42]. Such systems not only have the potential to warn workers close to dangerous machinery, but also to take action in the operation of the vehicle, should there be a serious danger to workers $[48,50,51]$.

Field tests have demonstrated the system's capability to provide a reliable and uniform marking zone around heavy vehicles $[38,48,50,51]$. The warning distance measurement results in RFID test systems having a good margin for collision avoidance, within the range of about $100 \mathrm{~m}$, allowed for by the high frequencies. Very low magnetic frequencies, allowing for a range of up to $30 \mathrm{~m}$, provide a lower margin for avoidance than high frequencies [54].

Installation considerations include reader placement, tag size, operating time (if self-powered), range, material penetration properties, orientation sensitivity, performance near metal structures (radio reflecting environments), susceptibility to interference (ducts and radiation), response times, multi-tag interaction, multiple readability, and physical orientation of the worker [24].

Passive systems are generally short range [24,52] and do not give any information on the action range, presenting a considerable sensitivity of orientation, as do the active systems. The latter require a battery in the tag [24], while the passive ones need a specific system for the battery power source [29]. The system makes use of sizeable equipment and is difficult to implement in hazardous areas [52].

The system using UHF frequencies suffers from a lack of accuracy in scope and is susceptible to metal or dielectric blind spots [52]. This may be because high-frequency magnetic fields can be affected by large metal objects $[44,48-50,54]$. Signal attenuation in UHF is increased in tunnel corners through diffraction and dispersion due to wall roughness [49].

Limitations $\quad$ Every vehicle or all personnel must be equipped with tags to be detected by the system [39,43,48]. Possible problems with this technology may include coverage issues [42]. No system provides the exact location of personnel, but only what is near; this could be a problem in the case of a number of people close to the vehicle, since is difficult to see who is really in danger $[23,54]$.

Field tests have highlighted tag detection problems caused by changes in physical orientation (e.g., if a worker bends down). The problem of directionality of tags can be reduced through a few directional antennas, either for tags or readers or through a pair of orthogonal antennas, to improve field force uniformity in all directions [47]. The height of the system antennas may influence the performance of the system [42]. Large electrically operated machinery can generate considerable amounts of electrical noise, so if the system receiver works at the same frequency band as this noise, it may not distinguish the type of signal $[48,50]$. Other potential sources of interference are communication devices operating at the same frequency band $[23,50]$. High-power electric systems, such as pumping stations and transformers, have been noted for their interference with electromagnetic field-based systems; thus, as with RF, every electromagnetic field-based system will suffer from possible interferences [23].

Advantageous combinations of technologies

Technology costs
These systems can be combined with lidar or radar because radio frequencies identify the nearby personnel, while radar/lidar provides accurate information on their position [23,43].

The technology using UHF electromagnetic frequencies has medium/low costs, including maintenance costs $[24,39,42,43]$, while low / very low magnetic frequency systems have medium/high costs [39].

The cost of some systems that represent an evolution of this technology, including the Hazardavert Proximity Detection System, is much higher than the cost of other collision sensors, but the potential of the technology justifies ongoing work to make this type of system much more reliable for all types of underground operations, such as mining $[40,47,48]$. 
Table 5. Cont.

\begin{tabular}{|c|c|}
\hline \multicolumn{2}{|r|}{ Ultrasonic Sensor-Based System } \\
\hline Principles and Characteristics & $\begin{array}{l}\text { Ultrasonic sensors are used for a variety of distance measurement and proximity detection applications [23], } \\
\text { as demonstrated by successful use in the automotive market, where parking assist sensors, for example, are } \\
\text { very common [23,24,47]. } \\
\text { These sensors use the speed of sound (by investing a target with ultrasonic energy) and the time between the } \\
\text { sound transmission and the return echo to determine the distance from an object [23-25,31]. Some of these } \\
\text { systems use separate sensors to transmit and receive; others combine both functions in a single sensor [24]. }\end{array}$ \\
\hline Advantages & $\begin{array}{l}\text { They are compact, relatively easy to install [24,34,55], and have a low energy consumption [55], proving } \\
\text { themselves to be an inexpensive system with considerable accuracy, allowing an action range up to about } 8 \mathrm{~m} \\
\text { [29,43,52]. } \\
\text { This technology has a minimum demand for infrastructure to be installed [29], with omni-directional sensors } \\
\text { providing good real-time detection [26] without requiring any wearable components from workers [25]. } \\
\text { Ultrasonic sensors are not affected by lack or change in visibility [33]. } \\
\text { These sensors can be used in an underground environment because data processing is simple, fast and not } \\
\text { affected by light, color or other objects (tests performed on locomotives underground) and uses separate } \\
\text { high-frequency receivers and transmitters [55]. }\end{array}$ \\
\hline Limitations & 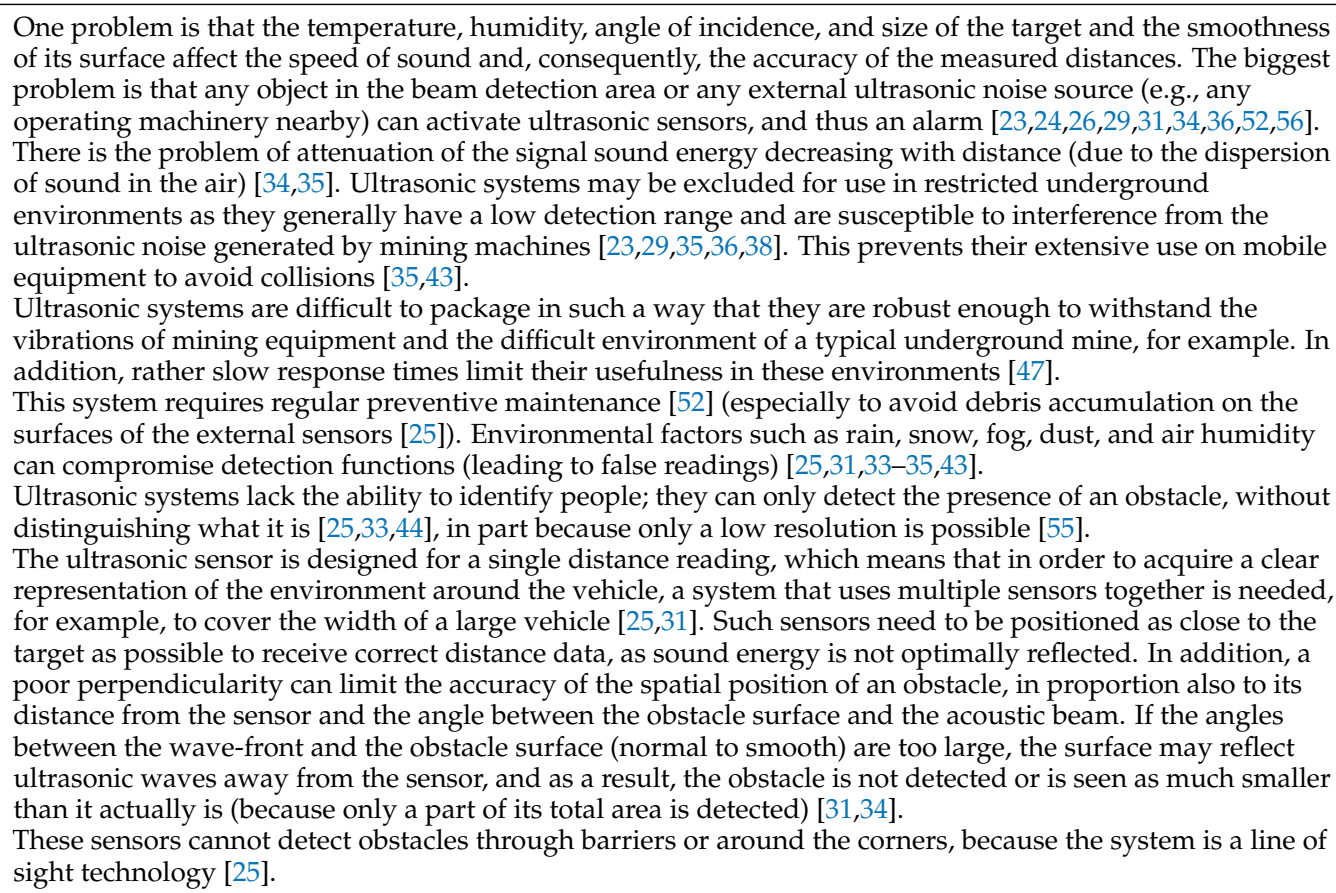 \\
\hline $\begin{array}{l}\text { Advantageous combinations of } \\
\text { technologies }\end{array}$ & $\begin{array}{l}\text { As this technology lacks the ability to identify people, it can be combined with camera systems, allowing the } \\
\text { operator to check directly from the monitor in the cabin as to what kind of obstacle has been registered [27,44]. }\end{array}$ \\
\hline Technology costs & Ultrasonic technology is inexpensive and also simple to use $[26,31,33-35,55,56]$. \\
\hline \multicolumn{2}{|r|}{ Lidar } \\
\hline Principles and Characteristics & $\begin{array}{l}\text { Infrared laser sensors are used in many industrial activities, not only for proximity alerts, but also for position } \\
\text { determination [24]. These systems work in a similar way to radar, except that they work by measuring the } \\
\text { time of flight and the speed of the infrared rays emitted by the scanner, which bounce from objects along their } \\
\text { path }[23,24,26,37] \text {. Laser scanners usually use a single laser and receiver and sweep the beam using a rotating } \\
\text { mirror [23]. The mirror angular position during reflection produces the direction of the detected object. The } \\
\text { combination of these values forms the basis for a complete profile of the surrounding environment within the } \\
\text { radial scan beam of the laser scanner [26,37]. Once the echo reaches the photo receiver of the laser scanner, the } \\
\text { received intensity is transformed into a voltage. The types of echo reflections can be different according to the } \\
\text { material. Different detection thresholds allow the separation and classification of these echoes, as a single } \\
\text { pulse can generate different echoes. The measuring scanner collects the reflections of the laser pulse, } \\
\text { processes the information, classifies the pulse reflections, and transmits the data via an Ethernet interface. If } \\
\text { an object is detected within the predefined alarm zones (adjustable according to the vehicle speed), a visual } \\
\text { alarm (on the cab display) and an audible warning to the driver is generated [37]. }\end{array}$ \\
\hline
\end{tabular}


Table 5. Cont

\begin{tabular}{|c|c|}
\hline \multicolumn{2}{|r|}{ Lidar } \\
\hline Advantages & $\begin{array}{l}\text { Laser-based proximity systems provide accurate distance measurements of all objects within a scanning area } \\
\text { up to approximately } 50 \mathrm{~m}[23,25,29,43,52,57] \text {. Using lidar/laser-based systems, interferences are unlikely } \\
\text { since another laser/lidar source must hit the exact same point at the same time to interfere [23]. An } \\
\text { interesting feature is their quick and precise depth measurement and wide field of view, making these sensors } \\
\text { particularly suitable for covering the area right in front of the vehicle [58] and offering the possibility of } \\
\text { programming this area [52]. This system is insensitive to sunlight or the environment and has standard } \\
\text { internal filters for glare (this applies especially to scanning lasers); thus, it work even in low light conditions } \\
\text { [31-34,59]. Overcoming the problems of dust penetration and vibration has opened the door to the } \\
\text { introduction of advanced multi-echo laser scanning technology, suitable, for example, for the difficult } \\
\text { underground mining environment [37]. Field tests have proven that laser scanners (e.g., SICK AG Company) } \\
\text { are reliable in applications with adverse weather conditions and in dusty environments. Their capability has } \\
\text { been demonstrated on a range of mining equipment [37,60]. The state-of-the-art laser/lidar scanners capture } \\
\text { high resolution and 3D information and can succesfully locate the target in different types of vehicles [26], } \\
\text { allowing a } 360^{\circ} \text { view [61]. Pulse radar is safe for vision (Class 1) [31,58,60,61]; considering not all laser-based } \\
\text { systems are safe, it should be carefully assessed [34]. It also allows measurement errors to be minimized, } \\
\text { compared, for example, to a continuous beam laser [31]. Scanning lasers offer better results for detection data } \\
\text { with much fewer constraints and demand for computational resources than, for example, camera detection, } \\
\text { and the resolution is significantly better than that of ultrasonic sensors [31,57]. Laser/lidar systems do not } \\
\text { require any wearable components by workers (e.g., tags) [23,25,60]. }\end{array}$ \\
\hline Limitations & $\begin{array}{l}\text { This system does not provide any information about what the object is, but only the presence of an object in a } \\
\text { certain position }[23,25,29,33,42,44,61] \text {, and it is a line of sight technology }[23,25] \text {. Environmental factors that } \\
\text { affect accuracy and impair detection include temperature, humidity, dust, water splashes (heavy rain), snow, } \\
\text { and fog }[24,31,33,35,52,55] \text {. In order to avoid detection failure under these conditions, further hardware and } \\
\text { software processing is carried out, such as multi-echo, adjustment of detection threshold, filtering, and } \\
\text { internal classification of dust [43]. Deposition problems on the sensor surface affect its detection function } \\
\text { (precautions need to be installed) [35,43].In addition, the materials that make up the laser systems are often } \\
\text { unstable and have a short life span, resulting in reliability problems (and therefore requiring considerable } \\
\text { maintenance) [34]. Accuracy is also influenced by the target size and reflectivity, surface roughness, and } \\
\text { geometric orientations [24,35,41,61]. As a system suitable for short-range detection [29], the use of } \\
\text { underground laser/lidar sensors is complicated by the close proximity of the tunnel walls [38]. These assume } \\
\text { the demand for infrastructure and a higher energy consumption than other sensors [26,34]. Laser scanner } \\
\text { scans are planar, which means that if an obstacle is above or below the scanning plane it is not detected (this } \\
\text { may be a serious problem if a worker is not detected and is in the path of a vehicle) [23,31]. }\end{array}$ \\
\hline $\begin{array}{l}\text { Advantageous combinations of } \\
\text { technologies }\end{array}$ & $\begin{array}{l}\text { Some systems already include GPS and V2V radio. There is a possibility of combination with radar and } \\
\text { camera [27,44]. A combination of thermal camera/camera and laser/lidar can use the former to identify } \\
\text { pedestrians and the latter to determine a precise distance from the person and trace it even if moving } \\
{[23,26,32,59] \text {. }}\end{array}$ \\
\hline Technology costs & $\begin{array}{l}\text { It is an expensive system and requires regular preventive maintenance }[29,31,39,52,55] \text {. 3D scanning lasers are } \\
\text { much more expensive than 2D lasers, given their complexity }[26,31,32,57] \text {. Typically, 1D and 2D lidar sensors } \\
\text { are less expensive and easier to package than radar [26]. }\end{array}$ \\
\hline \multicolumn{2}{|r|}{ Cameras } \\
\hline Principles and Characteristics & $\begin{array}{l}\text { Cameras allow the vehicle operator to control a blind spot area in real time through a monitor in the driver's } \\
\text { cab and are used in different industries [23,47]. Until recently, most camera-based systems were only driver } \\
\text { aids that did not provide active proximity detection, but thanks to the improvements in digital image } \\
\text { processing, this is changing [23]. They use optical sensors based on vision to track the approach of vehicles to } \\
\text { obstacles more effectively than active sensors, and in fact, thanks to visual info, they can provide a brief } \\
\text { description of the surrounding vehicles. Detection can be performed using stereo cameras as well as single or } \\
\text { multiple cameras. The cameras can be mounted either on the inside of the windscreen near the rear-view } \\
\text { mirror or on the rear of the vehicle. The use of both monocular and stereo-vision cameras typically manifests } \\
\text { itself in the use of monocular vision for detection and stereo vision for 3D tracking and tracing [26]. }\end{array}$ \\
\hline Advantages & $\begin{array}{l}\text { The first advantage to note is the practical nature of the system [24,26]. It is well tolerated by machine } \\
\text { operators and can be complementary to many other technologies [52]. The system makes it possible to } \\
\text { distinguish workers from other objects (compared to detection solutions by radar, ultrasound, and radio } \\
\text { frequencies) and allows a detection range of various dimensions [29,33,62]. It enables high resolutions and } \\
\text { wide viewing angles and a large amount of information in the image, and it is independent of any } \\
\text { modification of the infrastructure in the context, given the accumulation of data in a non-intrusive way } \\
\text { [26,33]. Since cameras do not emit any signals, they do not suffer from any problems of interference with } \\
\text { stimulation from the surrounding environment [58]. The 3D cameras continuously scan areas around } \\
\text { machine blind spots and reconstruct 3D environments, identifying the type of obstacle, both fixed and } \\
\text { moving [62]. CCD (Charge Coupled Device) cameras can be used and have the main advantage of allowing } \\
\text { the detection of large amounts of information [55]. Various cameras can provide information rich in texture } \\
\text { and color (which is missing from other types of sensors, e.g., laser/lidar) [59]. }\end{array}$ \\
\hline
\end{tabular}


Table 5. Cont.

\begin{tabular}{|c|c|}
\hline \multicolumn{2}{|r|}{ Cameras } \\
\hline Limitations & $\begin{array}{l}\text { Visible light cameras are commonly used for surface vehicles, but a system that uses visible light imaging to } \\
\text { function effectively in an underground mine would require its own light source, as otherwise the image } \\
\text { quality would suffer }[23,26,29,31-33,42,47,54,57,62] \text {. A further disadvantage of visible light imaging is that, if } \\
\text { a worker points light from helmet lamps directly at the camera, or when the camera is exposed to direct } \\
\text { sunlight, visibility problems may occur }[23,32,43] \text {. Video cameras are line of sight technologies and require a } \\
\text { high data processing effort }[23,29] \text {. } \\
\text { The operator is obliged to observe the monitor continuously to see what is happening around the machine, so } \\
\text { if the driver does not see a person or an obstacle, the camera is not able to help [23]. The system requires high } \\
\text { maintenance and cleanliness and is susceptible to moisture and dust }[29,47,52,54] \text {, as it may present deposit } \\
\text { problems on the sensor surface affecting its detection function (precautions need to be installed) [24,43]. Snow, } \\
\text { rain, dust, fog, and smoke result in visibility problems [26,29,31,33,38,43,54,62]. } \\
\text { A disadvantage of stereo vision is the inability to adapt quickly changing light conditions (which the human } \\
\text { eye is instead able to do). Long calculation times are required to correct this defect, which would greatly slow } \\
\text { down the detection system [31]. In many cases, more cameras may be required to achieve a full } 360^{\circ} \text { view of } \\
\text { the surrounding environment [26]. These systems require high computational resources to process images } \\
\text { (especially CCD cameras), particularly in the presence of backgrounds involving more complex environments } \\
\text { [26,32,33,55,57,58]. The accuracy of distance and velocity calculations is lower than for radar systems [33]. } \\
\text { There are some objects that can give false alarms in detections, which are strongly linked to lighting } \\
\text { conditions and, generally, to image quality (cleaning of the detection head window, detection head angle and } \\
\text { height, proximity of the object, reflections, strong backlight, very low visibility, etc.). Objects that may cause } \\
\text { false readings include, for example, images of life-size people, bushes, gas cylinders, etc. [62]. }\end{array}$ \\
\hline $\begin{array}{l}\text { Advantageous combinations of } \\
\text { technologies }\end{array}$ & $\begin{array}{l}\text { The cameras are not used for the automation of underground operations, but as a complementary element, as } \\
\text { a passive aid, or for remote control, making it possible to verify whether what has been detected by other } \\
\text { systems is really an obstacle [43]. }\end{array}$ \\
\hline Technology costs & $\begin{array}{l}\text { This is a low-cost technology }[25,31,33,39,57,58] \text {. In addition, the cost and size of the cameras continue to } \\
\text { decrease over time, making this obstacle detection method very popular [47]. }\end{array}$ \\
\hline \multicolumn{2}{|r|}{ Thermal Cameras/Infrared Rays (IR)—Machine Vision } \\
\hline Principles and Characteristics & $\begin{array}{l}\text { Alternatives to visible light imaging are thermal cameras, which are available for various motor vehicles and } \\
\text { can produce crisp images in complete darkness [23]. Thermal cameras create images based on thermal } \\
\text { radiation (long-wave infrared) received from the target. The camera receives results from the thermal } \\
\text { radiation emitted by the objects in the scenario (for passive thermal sensors) as well as radiation from other } \\
\text { sources reflected by the objects (for active thermal sensors) [23,24]. } \\
\text { The IR spectrum can be divided into four main areas: near IR (near visible light), short wavelength, medium } \\
\text { wavelength, and long IR wavelength. Near-infrared lighting is often used for night vision surveillance and } \\
\text { light-based distance sensors, such as time of flight (TOF) cameras and laser scanners. Long-wavelength IR (or } \\
\text { thermal IR) is the area of interest for proximity detection systems and is used for thermal imaging [41]. } \\
\text { Infrared light is suitable for indoor activities because human-made objects usually tend to reflect infrared } \\
\text { energy well [34]. }\end{array}$ \\
\hline Advantages & $\begin{array}{l}\text { Infrared cameras offer advantages that make them promising for use in underground environments; thermal } \\
\text { imaging does not require outdoor lighting, which gives it an advantage over imaging of systems with visible } \\
\text { light or near infrared [23,25,26,32,33,41,57]. } \\
\text { Their applications in mining, for example, include collision prevention for vehicles and other mining } \\
\text { equipment [36]. A thermal camera could help the driver to see further and be able to react sooner, which } \\
\text { would be a considerable help in driving [23]. It shows exactly where a person is in relation to a vehicle by } \\
\text { allowing the system to alert the operator to a potential collision [63]. } \\
\text { Both passive and active infrared sensors are good for long distances in fog, and active sensors can measure } \\
\text { vehicle speed [24]. The passive ones do not emit any electromagnetic energy and also do not interfere with } \\
\text { other underground systems [23]. } \\
\text { Machine vision provides a way to detect people, defining how many and exactly where they are in relation to } \\
\text { the hazardous areas around the vehicle [31,41]. } \\
\text { Infrared thermal imaging is not sensitive to blocking by dust. Thermal imaging illumination is radiated by } \\
\text { people, and the long wavelength (7-14 } \mu \text { m) allows it to penetrate mist, dust, and smoke [41]. An example of } \\
\text { this is the FLIR Systems Pathfinder thermal imaging camera [64]. } \\
\text { The false positive rate is very low, but the detection rate is influenced by the complexity of scenarios with } \\
\text { groups of people. In terms of temporal performance, the system has proven to be efficient for frame } \\
\text { processing times; however, this depends on the number of pedestrians present [65]. }\end{array}$ \\
\hline
\end{tabular}


Table 5. Cont.

\section{Thermal Cameras/Infrared Rays (IR)-Machine Vision}

Thermal cameras are line of sight technology and adopt intuitive methods for the operator to display the source of an alarm. However, despite a good precision in determining whether a person is, for example, in the path of a train or at long range, this technology is unable to determine whether the person is in a safe place or not (since it cannot determine the target's position with absolute precision) [23].

Passive infrared sensors can address precision problems in snow or rain conditions. For active sensors, the environmental problems affecting accuracy can be temperature, humidity, dust, and water splashes [24,33,52]. Thermal imaging is less effective in very hot environments due to the smaller temperature difference between pedestrians and the context. It loses its usefulness, especially outside, due to the inherent radiation emitted by soil, roads, and artefacts or objects, in addition to pedestrians, themselves $[34,57,65]$.

Infrared systems are liable to generate false alarms caused by direct sunlight, reflections, and very hot environments [47]. Therefore, infrared sensitivity to environmental conditions, in particular direct solar radiation, is a disadvantage [34].

Such systems require fairly high computational resources, as a result of the algorithms they exploit [32].

Advantageous combinations of

A combination of thermal camera and lidar or radar can use the thermal imager to identify pedestrians (since technologies it provides high angular resolutions) and lidar or radar to determine a precise distance from the person and trace the target even if moving. Moreover, the combination of these systems may give less chance of false alarms than the two systems individually [23].

Technology costs It is an inexpensive technology, especially for passive sensors, and is easy to program, which makes it a good candidate for being integrated with other technologies [32,52,57].

\section{Bluetooth-Beacon-Based Underground Proximity Warning System}

These are hardware transmitters, belonging to a class of energy-efficient Bluetooth devices, that transmit their signal (with a unique identification code) to portable electronic devices nearby, which detect it thanks to an app or a compatible operating system. Bluetooth wireless communication technology allows smartphones, tablets, and other devices to perform actions when they are near to a Bluetooth device $[54,66,67]$.

The system consists of the following main hardware components: signal transmitters, pedestrian receivers, equipment operator's receiver, and the software component that allows the reading function. Bluetooth data exchange functionality is achieved through ultra-high-frequency radio waves at a relatively short wavelength of around $2.4 \mathrm{GHz}$. Bluetooth technology is able to connect to multiple devices simultaneously in real time through an ad hoc network. The signal strength is used to calculate the distance between the beacon and the receiver [54].

The database stores the addresses of all Bluetooth beacons within the tunnel as well as the alarm images corresponding to each beacon. The system receives signals from the Bluetooth beacons, which are installed on workers' helmets, on the rear of vehicles, and in potentially dangerous areas, and provides the driver with progressive collision warning signals. When the vehicle approaches a worker or other hazard, the alarm message appears on the display [68].

Danger area beacons require only beacons in the identified danger areas; thus the demand for infrastructure is limited [23].

Previous studies have confirmed that Bluetooth systems are an appropriate technology for the automatic detection of human proximity in the workplace [67].

They do not require an external source of energy because they receive it from long-life batteries [54] [68] Moreover, being devices with a low energy demand, they lend themselves very much to large

implementations of systems, with new functions thanks to the development of compatible software and interface applications $[67,68]$. They are small, light, and easy to install everywhere and are made of resistant materials and are not vulnerable to moisture, making them especially suitable for use in tunnels $[54,68]$. Tests on Bluetooth systems conducted in the field showed a low number of false alarms, and the measurement results of the warning distance allowed a margin for collision avoidance. This is possible because danger area beacons will give the alarm when people and machines are both within range of the beacon; since the area in which the beacon is placed is identified as unsafe for personnel, the alarms are all considered true (this means that false alarms are unlikely; however, they are not impossible, because in some cases the signal could travel beyond the expected range) [23,54]. In addition, it has been found that the sound of the audible alarm was clearly differentiated from other common equipment alarms and workplace noise. The user interface of the mobile device is faster to calibrate than the devices of other proximity detection systems [54].

Attenuation of radio waves by rock masses is a significant factor to consider for the development of such a system, especially at excavation sites. The transmission characteristics of Bluetooth beacons may vary depending on the orientation in which they are installed (although they can be designed to propagate omnidirectionally). However, the tests performed do not guarantee the effectiveness for use in underground environments because the conditions vary a great deal depending on the specific context and take into account factors such as electromagnetic fields generated by the high number of electrical devices and installations, high humidity percentage, salinity, and the presence of particulates, which may influence the accuracy and reliability of such systems.

The transmission power of wearable devices is a parameter not adjustable on devices currently tested and available on the market. This could be a limiting factor for proximity detection applications [68]. 
Table 5. Cont.

\begin{tabular}{|c|c|}
\hline \multicolumn{2}{|r|}{ Bluetooth-Beacon-Based Underground Proximity Warning System } \\
\hline Technology costs & $\begin{array}{l}\text { The system costs are acceptable (including maintenance) for use in tunnels and safety management. The } \\
\text { equipment is not cumbersome, as it does not require the installation of a separate signal reception terminal, } \\
\text { since smartphones are used as receivers, and people tend to take these everywhere. The application of this } \\
\text { system can be shared as open source [68]. }\end{array}$ \\
\hline \multicolumn{2}{|r|}{ GPS (Global Positioning System) } \\
\hline Principles and Characteristics & $\begin{array}{l}\text { GPS systems are commonly used for surface operations. This type of system requires all surface personnel } \\
\text { and vehicles to be equipped with a GPS receiver (which receives the satellite signal) as well as a radio for } \\
\text { communication with nearby vehicles. Each vehicle transmits its position to the other vehicles within a defined } \\
\text { area, and a display in the vehicle shows the real-time position of the nearby vehicles, personnel, and other } \\
\text { stationary objects }[23,24,41,42] \text {. The system alerts the operator if there is an obstacle within a specified } \\
\text { range [23]. }\end{array}$ \\
\hline Advantages & $\begin{array}{l}\text { This is an excellent system for surface operations and can be used by a large number of people/vehicles } \\
\text { without affecting the quality of service, with good accuracy, and covering a large area [24]. It usually does not } \\
\text { have problems with the accumulation of material on the active sensors surface, nor does it have any problems } \\
\text { with dust, rain, snow, and fog [43]. } \\
\text { It has hazard reporting functionality without the use of tags and may be complementary to other } \\
\text { technologies [52]. }\end{array}$ \\
\hline Limitations & $\begin{array}{l}\text { The dependence of this system on satellite signals prevents its use in an underground environment deprived } \\
\text { of GPS. Therefore, any GPS-based system can be excluded for underground use, while it remains very valid } \\
\text { for surface work [23,24,29,41,42,52]. } \\
\text { The reliability/availability of the system depends a great deal on the environment in which it is located } \\
\text { [42,43]; it is also not suitable for short-range detection [29]. }\end{array}$ \\
\hline $\begin{array}{l}\text { Advantageous combinations of } \\
\text { technologies }\end{array}$ & $\begin{array}{l}\text { The use of GPS and wireless networks to transmit the location of a vehicle to all other vehicles in the area is } \\
\text { necessary [40]. }\end{array}$ \\
\hline Technology costs & $\begin{array}{l}\text { Collision avoidance systems using GPS-based technology have medium/low costs and require minimum } \\
\text { infrastructure for their operation }[29,39] \text {. }\end{array}$ \\
\hline
\end{tabular}

\subsection{The Contribution of Anti-Collision Systems to the Management of Shared Spaces: Examples of Applications}

In literature, there are many examples of applications of anti-collision systems in underground environments. These practical examples are useful to understand these systems possible applications and effectiveness in terms of risk management and in avoiding possible collisions between mobile vehicles and other vehicles, people, or underground structures.

Some of these examples are reported below (most of which deal with the testing of detection systems on equipment used in underground mines). They are useful qualitative feedback on the effective applicability of anti-collision systems and their usefulness in managing shared spaces in the reference context.

In the construction of the Marào Tunnel in Portugal $[2,69]$ and of the transalpine Alptransit tunnels (such as the base tunnels of Loetschberg, Ceneri, and Gotthard) [12], the contribution made by the application of video camera systems, especially rear-view ones, connected to a screen in the vehicle cabin (from which the operator could have better visibility of what was happening in the surrounding area) has been demonstrated. The application of these systems, following fatal accidents caused by collisions during construction work, resulted in a better risk approach by the operators, with a consequent decrease in the risk of collisions in the tunnel (demonstrated by the fact that there were no accidents associated with such a hazard from this time to completion of construction).

Anti-collision systems that have been designed and tested during underground operations and are available on the market are as follows:

- The HASARD system (developed by NIOSH), which is an active proximity detection system that uses low-frequency magnetic fields and has been successfully tested on mining equipment (for example continuous miners) in difficult environments such as those underground. Several manufacturers have refined the technology proposed by NIOSH researchers [25].

- The FEATureFACE project, which has been used to test the performance of individual systems on equipment used underground, in order to create an innovative anti-collision system that exploits the advantages of the combination of various tech- 
nologies (including radar, ultra-high-frequency RFID, sound-based localization, and low-frequency magnetic field technology) to increase safety levels [30].

- StrataWorldwide's HazardAVERT ${ }^{\circledR}$ Proximity Detection System, which is an example of detection-based technology using low-magnetic radio frequency technologies that are unaffected by environmental and climatic conditions as well as ultra-high frequencies (UHFs). This is an evolution obtained through an adaptation of the HASARD Proximity Detection System (originally developed by NIOSH), used in underground coal mines. This system has been proven to be practical for underground applications, for mobile equipment, and with people on foot working nearby. It also can be used in confined workspaces and with limited visibility, with people interacting with numerous machines at the same time, and with people and/or vehicles hidden behind corners, visual obstacles, and/or barriers of various types [48,50]. The system provides multiple areas, ensuring a discrete distance range of up to $25 \mathrm{~m}[48,70]$.

- Becker Mining South Africa PTY Ltd. Collision Avoidance System, which is a hybrid system that exploits multiple detection technologies, namely, electromagnetic fields for short range detections and high and ultra-high frequency (UHF) detection to extend the detection range. It is used for both underground and surface applications [25,52].

- Booyco Collision Warning System (for example Booyco CWS 800), which uses a combination of very low (VLF) and ultra-high (UHF) radio frequencies, with a detection range of up to $15 \mathrm{~m}$. This system was applied in an underground copper mine in Zambia, where it increased awareness and minimized accidents by alerting both machine operators and workers on foot [71,72].

- Nautilus Coal-Buddy [73], which exploits magnetic fields and was used for miners in underground mines.

- Minesic tunnel collision warning (manufactured by SICK), which is a powerful anticollision and driving assistance system in tunnels. It is suitable for use with most underground mining vehicles. This robust system, based on modern laser scanners and special sensors, provides safe maneuvering for vehicles in close proximity to tunnel walls, allowing the vehicle operator a better view of the surrounding environment thanks to the in-cab monitor guide. It permits the detection of moving and static obstacles, without the need for the use of RFID tags, with a low rate of false alarms and a detection range of up to $50 \mathrm{~m}[43,61]$.

- FLIR thermal imaging cameras, such as PathFindIR (connected to a display in the driver's cab), which are not sensitive to dust and dark conditions and are suitable for underground use [64].

- Bluetooth beacons, which were tested in [68] by installing the devices along the walls of the tunnel, on the safety helmets of the workers on foot, and on the rear of vehicles.

In addition to the examples obtained from the literature, there is the experience of some authors of the application of a system with radiofrequency tags (Figure 4), during the construction of the base tunnel of the Lyon-Turin railway line (TELT site at Saint Martin La Porte). In this case, every worker on the site wore a tag/badge (including vehicle operators), and an audible/light alarm signal was placed in the operator's cabin to warn the vehicle operator of the presence of other workers walking in the proximity of the vehicle, from a distance of about $3 \mathrm{~m}$. The alarm in the cabin sounded even if the operator did not have a valid authorization to proceed with the vehicle; when driving the vehicle, the driver had to deactivate the tag; if the tag was not deactivated, the tag would be detected by the system and trigger the warning alarm.

This system was used after an accident occurred during the construction of the tunnel, which involved a pedestrian crushed by a vehicle. The application of the system has proven to be very effective, helping to increase the level of safety and improve health conditions in the tunnel construction works. In fact, no more accidents occurred. 


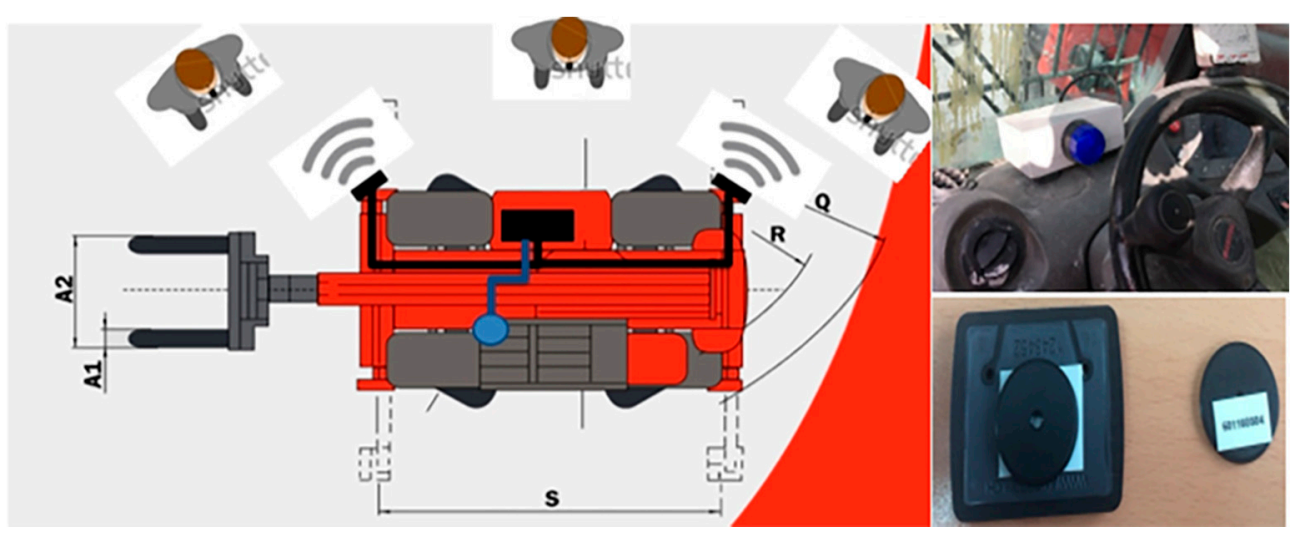

Figure 4. Application of radio-frequency tag-based system, with details of cabin alarm (top right) and the tag/badge wearable by workers (bottom right).

Furthermore, infrared light anti-collision sensors (Figure 5), ultrasonic sensors (Figure 6), and radar sensors (Figure 7) were used at the same site. These were applied to the wheeled vehicles for the transport of the prefabricated segments that made up the final lining of the tunnel. These systems showed considerable effectiveness, both in detecting the distance of the vehicle from the tunnel walls (thus avoiding collisions with structural elements) and in detecting workers on foot or other obstacles.

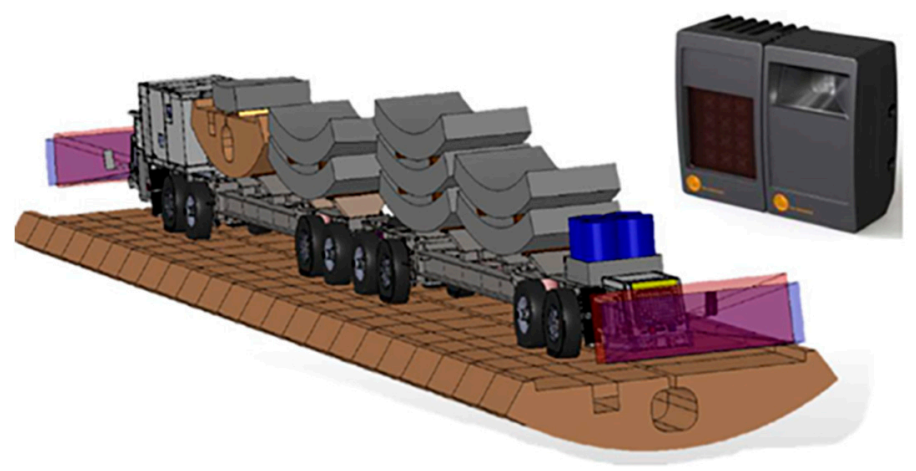

Figure 5. Camera 3D-Infrared light emitting sensor, which allows a detection distance of 50-70 m.

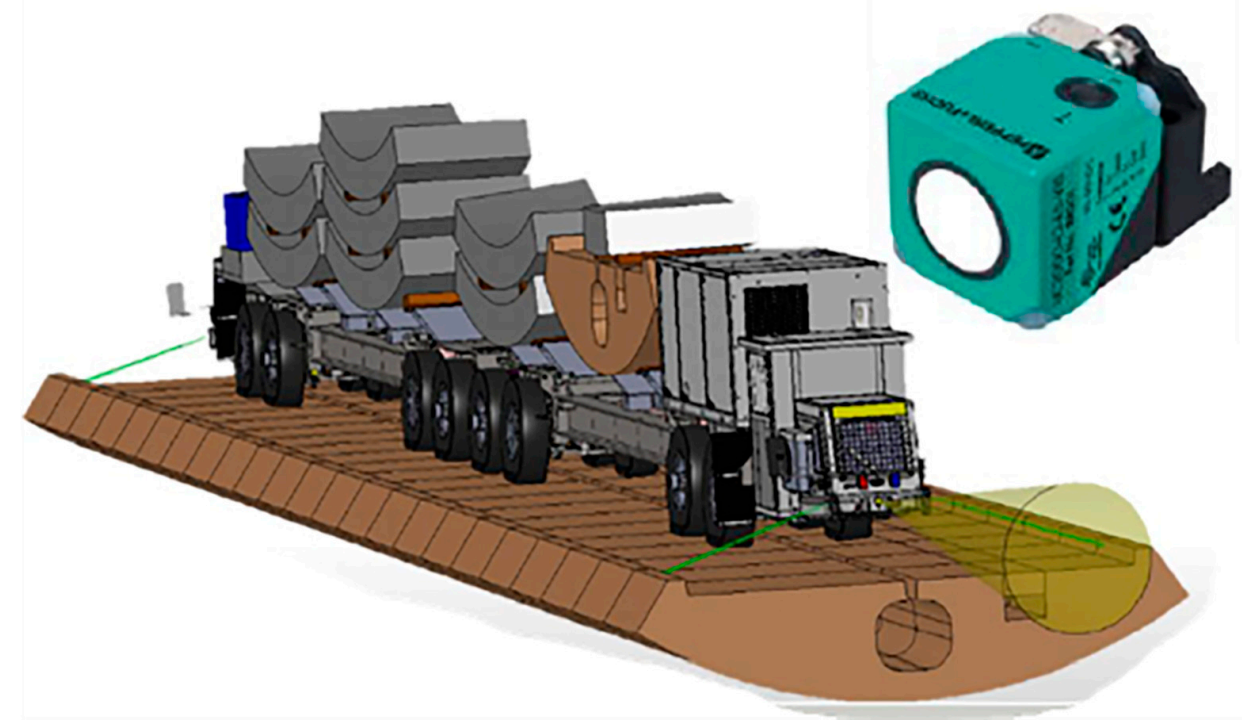

Figure 6. Ultrasonic sensor, which transmits the detection information to the driver's cab by means of warning lights of different colors. 


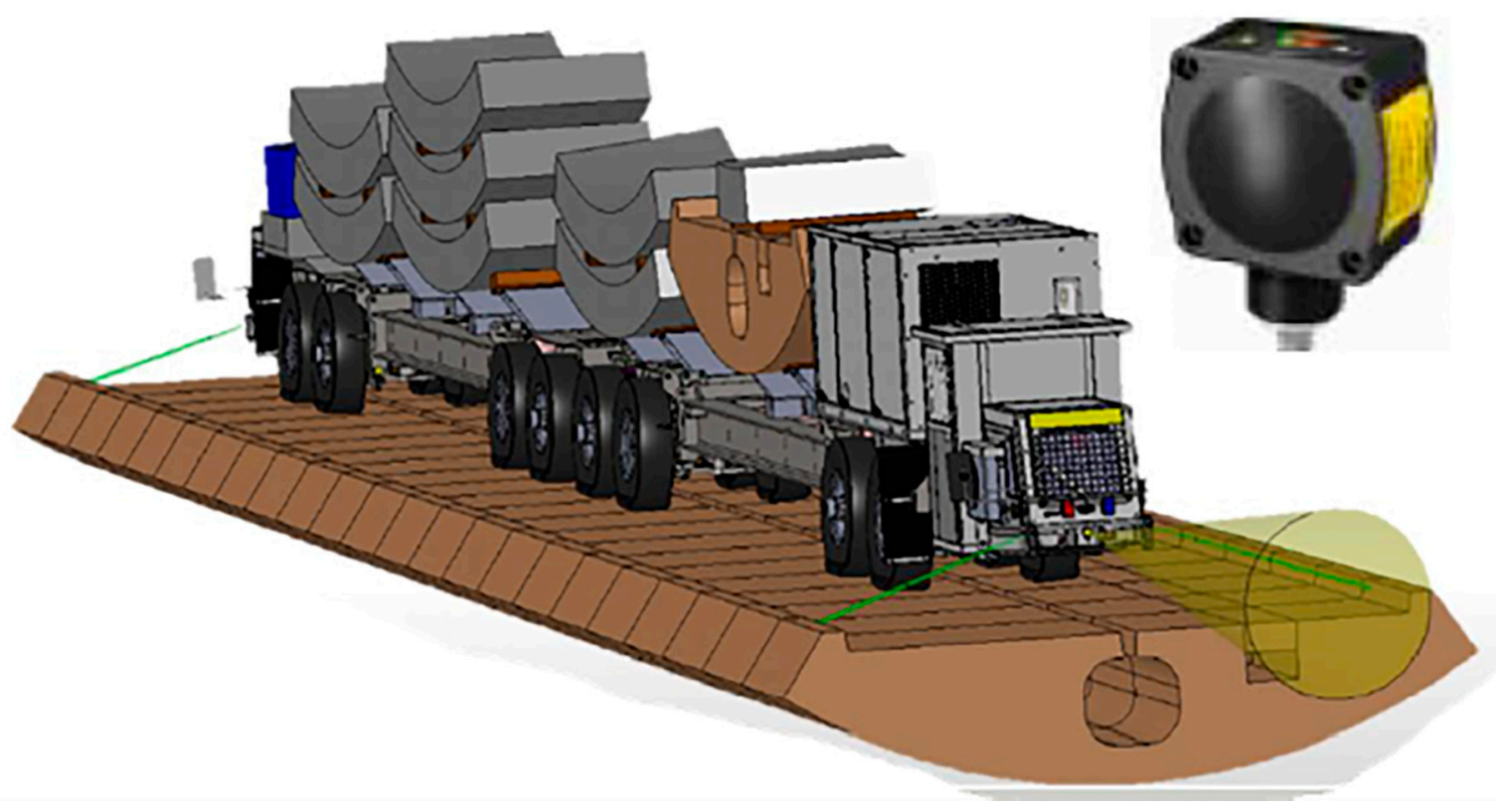

Figure 7. Radar positioned in front of the vehicle's cockpit; detection distance of $24 \mathrm{~m}$.

\section{Discussion}

This study pointed out that RFID/RF-Radio Frequency Identification is the most widely used and is often implemented with other technologies.

The less expensive technologies reported in the literature appear to be ultrasonic sensor-based systems and cameras, while lidar/laser systems are the most expensive and require high maintenance.

In general, the available anti-collision systems are currently used for large obstacles; however, in the future, it would be interesting to study suitable solutions to signal the presence of fixed or mobile obstacles to incoming vehicles resulting from exceptional situations. Therefore, it would be of considerable use if any obstacle could be equipped with an emergency beacon. At the moment, the solution consists of a careful positioning of the structural components.

If the accident case analyzed previously with the CСCP approach is evaluated using the functional volumes method (distinguishing the protection volume from the physical volume of the moving vehicle), it is possible to state that, by equipping the vehicle with anticollision systems, the operator's reaction time can become sufficient to prevent accidents.

\section{Limitations}

The total comprehensiveness of the study cannot be guaranteed in such a vast and evolving field, despite efforts to extend the bibliographic research.

Nevertheless, since the subject under study is extremely topical, sufficient comprehensiveness has been acquired to demonstrate the applicability of such systems in the context considered, bearing in mind that there will certainly be further developments in the future.

\section{Conclusions}

From the systematic analysis of the literature, it is clear that anti-collision systems have so far found limited application in the underground excavation sites of civil works. However, the problem seems significant since, even with a limited sample, it is estimated that in the working conditions (limited space, non-optimal lighting, unclear atmosphere, and crowding of self-propelled vehicles of great power and considerable bulk), the risks of interference between structures and pedestrians cannot be overlooked. The improvement in terms of safety and efficiency that would potentially be made possible by the 
new automated anti-collision solutions would therefore be considerable, even though the introduction of each new technology requires a careful predictive risk assessment in terms of production efficiency, availability, and OS\&H. A timely field check of the real performance in the specific context must be then carried out.

A future research direction seems to be the use of these technologies simultaneously in a combined system. Thus, if one technology fails, the other can guarantee the functioning of the system.

The RFID/RF-Radio Frequency Identification, ultrasonic sensor-based systems, and cameras appear to be suitable to be implemented in a combined system, because RFID/RF is the most widely used and the other two are inexpensive and easy to implement.

This work will be improved thanks to the possibility of in-field testing of some of the discussed devices, as part of the expected start of important tunnelling infrastructural TELT projects in the alpine region of northwest Italy.

Author Contributions: Conceptualization, M.P. and A.S.; methodology, R.N.; investigation, S.P.; resources, A.S.; writing-original draft preparation, S.P., M.P., R.N. and E.P.; supervision, M.P. and E.P. All authors have read and agreed to the published version of the manuscript.

Funding: This research was funded by TELT SAS.

Institutional Review Board Statement: Not applicable.

Informed Consent Statement: Not applicable.

Data Availability Statement: All data related to the literature review can be found on Google Scholar web search engine.

Conflicts of Interest: The authors declare no conflict of interest.

\section{References}

1. Labagnara, D.; Patrucco, M.; Sorlini, A. Cap. 12: Aspetti tecnologici di valutazione e gestione del rischio nei cantieri in sotterraneo. In Ingegneria Forense: Metodologia, Protocolli, Casi Studio; Augenti, N., Chiaia, B.M., Eds.; Dario Flaccovio Editore: Palermo, Italy, 2011.

2. Tender, M.L.; Martins, F.F.; Couto, J.P.; Pérez, A.C. Study on prevention implementation in tunnels construction: Marão Tunnel's (Portugal) singularities. Rev. Constr. 2017, 16, 262-273. [CrossRef]

3. Centers for Desease Control and Prevention (CDC). Workplace Safety and Health Topics. Prevention through Design. Available online: https:/ / www.cdc.gov/niosh/topics/ptd/default.html (accessed on 18 October 2020).

4. De Cillis, E.; Labagnara, D.; Maida, L.; Masucci, C. Valutazione e gestione dei rischi per la salute dei lavoratori nello scavo meccanico di gallerie. GEAM 2014, 143, 93-103.

5. Guglielmetti, V.; Grasso, P.; Ashraf, M.; Xu, S. Cap. 7: Health and Safety. In Mechanized Tunnelling in Urban Areas-Design Methodology and Construction Control; Tailor \& Francis Group: London, UK, 2008; pp. 279-296.

6. Faranda, A.; Labagnara, D.; Maida, L.; Patrucco, M.; Sorlini, A. Modellazione 3D a supporto del metodo dei Volumi Funzionali per la ottimizzazione di efficienza e sicurezza in un cantiere per scavo di galleria. PinC 2017, 1, $43-47$.

7. Labagnara, D.; Maida, L.; Patrucco, M.; Sorlini, A. Analysis and management of spatial interferences: A valuable tool for operations efficiency and safety. GEAM 2016, 149, 35-43.

8. Tender, M.L.; Couto, J.P. "Safety and Health" as a criterion in the choice of tunnelling method. In Occupational Safety and Hygiene; Taylor \& Francis Group: London, UK, 2016; Volume IV, pp. 153-157.

9. Ciocan, C.; DeCillis, E.; Donato, F.; Garzaro, G.; Patrucco, M.; Pira, E. Evoluzione del concetto di OS\&H dal secondo dopoguerra ad oggi: Dal sistema prescrittivo alla Valutazione e Gestione dei rischi in qualità di sistema-Il modello esteso in collaborazione alle grandi strutture. Evoluzione della cultura multidisciplinare della sicurezza e OS\&H. GEAM 2018, 2, 16-20.

10. United States Department Of Labour (DOL). Bureau of Labour Statistics. Census of Fatal Occuaptional Injuries. Available online: https:/ / www.bls.gov/iif/oshcfoi1.htm (accessed on 15 April 2020).

11. Safe Work Australia. Work-Related Traumatic Injury Fatalities. Available online: https://www.safeworkaustralia.gov.au/ collection/work-related-traumatic-injury-fatalities (accessed on 15 April 2020).

12. Vogel, M.; Kunz-Vondracek, I. Safety and health in long deep tunnelling-Lessons learned on Swiss transalpine tunnel projects. In Proceedings of the Underground. In The Way to the Future; CRC Press: Boca Raton, FL, USA, 2013; pp. $1651-1658$.

13. De Cillis, E.; Patrucco, M.; Maida, L. Computer-aided advanced technique for the analysis of occupational accidents. In Proceedings of the WOS 8th Internacional Conference-Smart Prevention for Sustainable Safety, Porto, Portugal, 23-25 September 2015; pp. 404-414.

14. Luzzi, R.; Passannanti, S.; Patrucco, M. Advanced technique for the in-depth analysis of occupational accidents. CET 2015, 43, 1219-1224. 
15. Pentimalli, S. In-Depth Analysis of Accidents for Prevention: Implementation of A Specific Computer-Aided Approach for Underground Activities (Submission of a Technical Paper on the Topic to a Scientific Magazine Pending). Bachelor's Thesis, Degree in Environment and Workplace Prevention Techniques, University of Turin, Turin, Italy, 2019.

16. European Union Law. Council Directive 92/57/EEC of 24 June 1992 on the Implementation of Minimum Safety and Health Requirements at Temporary or Mobile Construction Sites (Eighth Individual Directive within the Meaning of Article 16 (1) of Directive 89/391/EEC); Grand Duchy of Luxembourg: Luxembourg, 1992.

17. Istituto Nazionale Assicurazione Contro gli Infortuni sul Lavoro (INAIL). Available online: https://www.inail.it (accessed on 20 April 2020).

18. De Cillis, E.; Fargione, P.; Maida, L.; Sambuelli, L. Present and future contribution of geophysics to the prevention through design and quality management approaches for tunneling operations. First Break 2018, 36, 35-41. [CrossRef]

19. Labagnara, D.; Patrucco, M.; Rossetti, P.; Pellegrino, V. Predictive assessment of the asbestos content in the Western Italian Alps: An essential tool for an effective approach to risk analysis and management in tunneling operations and muck reuse. Environ. Earth Sci. 2012, 70, 857-868. [CrossRef]

20. Moher, D.; Liberati, A.; Tetzlaff, J.; Altman, D.G.; The PRISMA Group. Preferred reporting items for systematic reviews and meta-analyses: The PRISMA statement. PLoS Med. 2009, 6, e1000097. [CrossRef]

21. Pereira, F.J.L. Positioning Systems for Underground Tunnel Environments. Ph.D. Thesis, University of Porto, Prto, Portugal, 2016.

22. Patrucco, P. Electromagnetic Communications through the Ground: Applications for Underground Construction Sites. Bachelor's Thesis, Degree in Electronic Engineering, Politecnico of Turin, Turin, Italy, 1993.

23. Dickens, J.; Green, J.; Teleka, R.; Sabatta, D. A Global Survey of Systems and Technologies Suitable for Vehicle to Person Collision Avoidance in Underground Rail-Bound Operations; Mine Health and Safety Council: Woodmead, South Africa, 2014.

24. National Institute of Occupational Health and Safety-NIOSH. Engineering Considerations and Selection Criteria for Proximity Warning Systems for Mining Operations. Available online: http://www.cdc.gov/niosh/mining/content/pwsselection.html. (accessed on 20 June 2020).

25. DuCarme, J. Developing effective proximity detection systems for underground coal mines. In Advances in Productive, Safe, and Responsible in Coal Mining; Hirschi, J., Ed.; Elsevier: Amsterdam, The Netherlands, 2018; pp. 101-119.

26. Mukhtar, A.; Xia, L.; Tang, T.B. Vehicle Detection Techniques for Collision Avoidance Systems: A Review. IEEE Trans. Intell. Transp. Syst. 2015, 16, 2318-2338. [CrossRef]

27. Ruff, T.M. Recommendations for Testing Radar-Based Collision Warning Systems on Heavy Equipment. NIOSH. Report of Investigations-RI 9657. 2002. Available online: https://www.cdc.gov/niosh/mining/userfiles/works/pdfs/ri9657.pdf (accessed on 24 July 2020).

28. Ruff, T.M. Application of Radar to Detect Pedestrian Workers Near Mining Equipment. Appl. Occup. Environ. Hyg. 2001, 16, 798-808. [CrossRef] [PubMed]

29. Marks, E.D.; Teizer, J. Method for testing proximity detection and alert technology for safe construction equipment operation. Constr. Manag. Econ. 2013, 31, 636-646. [CrossRef]

30. Neumann, K.; Berg, J.; Eichentopf, B.; Mehnert, P.; Nienhaus, K. Featureface-an innovative collision avoidance system for the underground mining industry. In Proceedings of the 37th International Symposium: APCOM (Application of computers and operations re-search in the mineral industry), Englewood, CO, USA, 25-28 May 2015; pp. 767-784.

31. Gray, K.W. Obstacle Detection and Avoidance for an Autonomous Farm Tractor. Matser's Thesis, Utah State University, Logan, UT, USA, 2000.

32. Gandhi, T.; Trivedi, M. Pedestrian collision avoidance systems: A survey of computer vision based recent studies. In Proceedings of the 2006 IEEE Intelligent Transportation Systems Conference, Toronto, ON, Canada, 17-20 September 2006; IEEE: New York, NY, USA, 2006; pp. 976-981.

33. Pratyush, B. Vehicle Technologies to Improve Performance and Safety. UC Berkeley Earlier Faculty Research. 2003. Available online: https:/ / escholarship.org/uc/item/4zw4m05k (accessed on 17 July 2020).

34. Jansen, N.F. Short Range Detection and Avoidance; Traineeship Report; Eindhoven University of Technology: Eindhoven, The Netherlands, 2010.

35. Brooker, G.M.; Hennessey, R.; Lobsey, C.; Bishop, M.; Widzyk-Capehart, E. Seeing through dust and water vapor: Millimeter wave radar sensors for mining applications. J. Field Robot. 2007, 24, 527-557. [CrossRef]

36. Kiziroglou, M.E.; Boyle, D.E.; Yeatman, E.M.; Cilliers, J.J. Opportunities for Sensing Systems in Mining. IEEE Trans. Ind. Informatics 2017, 13, 278-286. [CrossRef]

37. Guenther, N.; Duncan, D.; Harrison, P.; De Kock, A. The Application of Laser Sensing Technology to Proximity Detection in the Mining Industry. Available online: https:/ / www.qmihsconference.org.au/wp-content/uploads/qmihsc-2010-writtenpaperguenther.pdf (accessed on 17 July 2020).

38. Jobes, C.C.; Carr, J.L.; DuCarme, J.P. Evaluation of an advanced proximity detection system for continuous mining machines. IJAER 2012, 7, 649-667.

39. Jo, B.-W.; Lee, Y.-S.; Kim, J.-H.; Kim, D.-K.; Choi, P.-H. Proximity Warning and Excavator Control System for Prevention of Collision Accidents. Sustain. J. Rec. 2017, 9, 1488. [CrossRef]

40. Ruff, T.M. Advances in proximity detection technologies for surface mining equipment. In Proceedings of the 34th AIMHSR, Salt Lake City, UT, USA, 25 May 2004. 
41. Dickens, J.S.; Van Wyk, M.A.; Green, J.J. Pedestrian detection for underground mine vehicles using thermal images. In Proceedings of the IEEE Africon '11, Victoria Falls, Zambia, 13-15 September 2011; IEEE: New York, NY, USA, 2011; pp. 1-6.

42. Kloos, G.; Guivant, J.E.; Nebot, E.M. Range based localisation for mining safety-RFID based system to detect the presence of personnel in close proximity to large machines. In Proceedings of the International Conference on Intelligent Robots and Systems, Beijing, China, 9-13 October 2006.

43. Guenther, N.; Salow, H. Collision avoidance and operator guidance innovating mine vehicle safety. In Proceedings of the Queensland Mining Industry Health \& Safety Conference, Townsville, Australia, 19-12 August 2012.

44. Teizer, J. Magnetic Field Proximity Detection and Alert Technology for Safe Heavy Construction Equipment Operation. In Proceedings of the 32nd International Symposium on Automation and Robotics in Construction and Mining (ISARC 2015), International Association for Automation and Robotics in Construction (IAARC). Oulu, Finland, 15-18 June 2015; pp. 1-9.

45. World Heath Organization (WHO). Home/Newsroom/Q\&A Detail/Radiation: Radar. Available online: https://www.who.int/ news-room/q-a-detail/radiation-radar (accessed on 10 April 2020).

46. Ruff, T. Evaluation of a radar-based proximity warning system for off-highway dump trucks. Accid. Anal. Prev. 2006, 38, 92-98. [CrossRef]

47. Ruff, T.M.; Hession-Kunz, D. Application of Radio-Frequency Identification Systems to Collision Avoidance in Metal/Non-metal Mines. IEEE Trans. Ind. Appl. 2001,37, 112-116. [CrossRef]

48. Kent, D.; Schiffbauer, B. Proximity Detection Systems in Underground Mines. In Proceedings of the Queensland Mining Industry-Health and Safety Conference, Queensland, Australia, 2014; Available online: https:/ / www.qmihsconference.org.au / wp-content/uploads/qmihsc-2010-writtenpaper-kent.pdf (accessed on 10 April 2020).

49. Mishra, P.K.; Stewart, R.F.; Bolic, M.; Yagoub, M.C.E. RFID in Underground-Mining Service Applications. IEEE Pervasive Comput. 2014, 13, 72-79. [CrossRef]

50. Schiffbauer, W.H. An Active Proximity Warning System for Surface and Underground Mining Applications. Min. Eng. 2002, 54.

51. Schiffbauer, W.H.; Mowrey, G.L. An environmentally robust proximity warning system for hazardous areas. In Proceedings of the ISA Emerging Technologies Conference-Instrument Systems and Automation Society, Houston, TX, USA, 10-13 September 2001; pp. 1-10.

52. Becker Mining. ProximityDetection and CollisionAvoidance System. Available online: http://www.undergroundcoal.com.au/ acarp_dev/May\%202011/Proximity\%20Detection\%20and\%20Collision\%20Avoidance\%20-\%20Stephan\%20Becker.pdf (accessed on 15 April 2020).

53. STRATA Worldwide. HazardAvert Surface and Underground. Available online: https://www.mining-technology.com/ contractors/communications / proximity-detection/\#company-details (accessed on 22 June 2020).

54. Park, J.; Marks, E.; Cho, Y.K.; Suryanto, W. Performance Test of Wireless Technologies for Personnel and Equipment Proximity Sensing in Work Zones. J. Constr. Eng. Manag. 2016, 142, 4015049. [CrossRef]

55. Jianxia, D. Design and implementation of underground locomotive collision avoidance system. Appl. Mech. Mater. Trans Tech Publ. 2015, 741, 744-748.

56. Bhandari, P.; Zagade, Y.; Parth, M.P.; Soni, D.N. Ultrasonic Collision Prevention System for Vehicles. IJARCET $2016,5,749-753$.

57. Gandhi, T.; Trivedi, M.M. Pedestrian Protection Systems: Issues, Survey, and Challenges. IEEE Trans. Intell. Transp. Syst. 2007, 8, 413-430. [CrossRef]

58. Gavrila, D. Sensor-based pedestrian protection. IEEE Intell. Syst. 2001, 16, 77-81. [CrossRef]

59. Wei, P.; Cagle, L.; Reza, T.; Ball, J.; Gafford, J. LiDAR and Camera Detection Fusion in a Real-Time Industrial Multi-Sensor Collision Avoidance System. Electronics 2018, 7, 84. [CrossRef]

60. Fuerstenberg, K.; Willhoeft, V. Object tracking and classification using laserscanners-pedestrian recognition in urban environment. In Proceedings of the ITSC 2001, 2001 IEEE Intelligent Transportation Systems (Cat. No.01TH8585), Oaklands, CA, USA, 25-29 August 2001; IEEE: New York, NY, USA, 2002; pp. 451-453.

61. SICK. Minesic100TCW. Available online: https://www.sick.com/it/it/soluzioni-per-sistemi/sistemi-di-assistenza-alconducente/minesic100-tcw/minesic100-tcw/p/p355946?ff_data=JmZmX21kPXAzNTU5NDYmZmZfbWFzdGVySWQ9 cDM1NTk0NiZmZ190aXRsZT1NSU5FU01DMTAwIFRDVyZmZ19xdWVyeT0mZmZfcG9zPTEmZmZfb3JpZ1Bvcz0xJmZmX3 BhZ2U9MSZmZ19wYWdlU216ZT0yNCZmZ19vcmlnUGFnZVNpemU9MjQmZmZfc2ltaT05NC4w (accessed on 27 July 2020).

62. Blaxtair. Pedestrian Proximity Detection. Available online: https:// blaxtair.com/ (accessed on 16 April 2020).

63. Dickens, J. Thermal imagery predicts pedestrian-vehicle collisions in mines. PositionIT 2012, 38, 66-67.

64. FLIR. Available online: www.flir.com (accessed on 23 June 2020).

65. Bertozzi, M.; Broggi, A.; Fascioli, A.; Graf, T.; Meinecke, M.-M. Pedestrian Detection for Driver Assistance Using Multiresolution Infrared Vision. IEEE Trans. Veh. Technol. 2004, 53, 1666-1678. [CrossRef]

66. Addey, D. iBeacons. 2013. Available online: https://web.archive.org/web/20131203014352/http://daveaddey.com/?p=1252 (accessed on 29 July 2020).

67. Montanari, A.; Nawaz, S.; Mascolo, C.; Sailer, K. A Study of Bluetooth Low Energy performance for human proximity detection in the workplace. In Proceedings of the 2017 IEEE International Conference on Pervasive Computing and Communications (PerCom), Kona, HI, USA, 13-17 March 2017; IEEE: New York, NY, USA, 2017; pp. 90-99.

68. Baek, J.; Choi, Y. Bluetooth-Beacon-Based Underground Proximity Warning System for Preventing Collisions inside Tunnels. Appl. Sci. 2018, 8, 2271. [CrossRef] 
69. Tender, M.; Couto, J.; Baptista, J.; Garcia, A. Topics for the prevention of accidents in tunnels—The Marào Tunnel experience. In Occupational Safety and Hygiene; Taylor \& Francis: London, UK, 2017; Volume V, pp. 257-261.

70. STRATA Worldwide. Available online: https://www.strataworldwide.com/download-file/1916 (accessed on 22 April 2020).

71. Booyco Electronics. Available online: https://www.engineerit.co.za/engineerit/booyco-454-07-cws800-collision-warningsystem-crosses-the-border-to-zambia/ (accessed on 22 April 2020).

72. Booyco Electronics. Available online: https://www.booyco-electronics.co.za/product-range/proximity-detection-system-pds (accessed on 22 April 2020).

73. Nautilus International. Mining Automation and Remote Controls. Nautilus Coal-Buddy. Available online: http://www.nautilusintl.com/proximity-detection/nautilus-coal-buddy-operators-proximity-detection-system-for-underground-coal-minesoperating-in-an-explosive-methane-gas-environment-class-i-div-ii/nautilus-coal-buddy-proximity-detection-device-pdd / (accessed on 22 May 2020). 